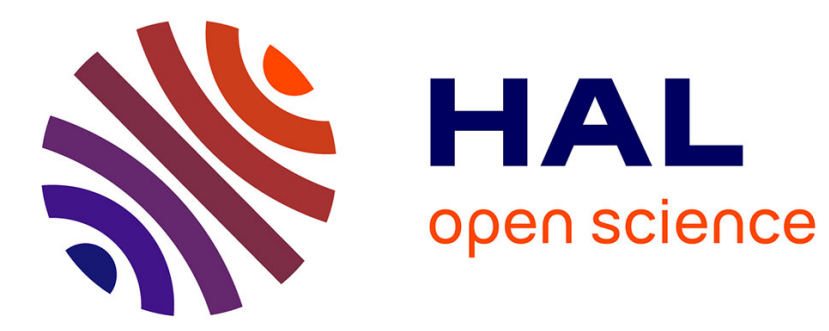

\title{
Putting time in a wider perspective: The past, the present, and the future of time perspective theory
}

Maciej Stolarski, Nicolas Fieulaine, Philip G Zimbardo

\section{To cite this version:}

Maciej Stolarski, Nicolas Fieulaine, Philip G Zimbardo. Putting time in a wider perspective: The past, the present, and the future of time perspective theory. The SAGE handbook of personality and individual differences, 2018, 10.4135/9781526451163.n28 . hal-02419830

\section{HAL Id: hal-02419830 \\ https://hal.science/hal-02419830}

Submitted on 19 Dec 2019

HAL is a multi-disciplinary open access archive for the deposit and dissemination of scientific research documents, whether they are published or not. The documents may come from teaching and research institutions in France or abroad, or from public or private research centers.
L'archive ouverte pluridisciplinaire HAL, est destinée au dépôt et à la diffusion de documents scientifiques de niveau recherche, publiés ou non, émanant des établissements d'enseignement et de recherche français ou étrangers, des laboratoires publics ou privés. 


\section{Putting time in a wider perspective:}

\section{The past, the present, and the future of time perspective theory}

Maciej Stolarski ${ }^{1}$, Nicolas Fieulaine ${ }^{2}$ \& Philip G. Zimbardo ${ }^{3}$

${ }^{1}$ Faculty of Psychology, University of Warsaw, Warsaw, Poland; mstolarski@psych.uw.edu.pl

${ }^{2}$ Institute of Psychology, Lumière University Lyon 2, Lyon, France; nicolas.fieulaine@univ-lyon2.fr

${ }^{3}$ Department of Psychology, Stanford University, Stanford, CA, USA;

drzimbardo@gmail.com

This is an initial Authors' version of a chapter published in The SAGE Handbook of Personality and Individual Differences, edited by Virgil Zeigler-Hill and Todd K. Shackelford (Thousand Oakes, CA: SAGE, 2018).

The citation for the final published version is:

Stolarski, M., Fieulaine, N., \& Zimbardo, P. G. (2018). Putting time in a wider perspective: The past, the present, and the future of time perspective theory. In V. Zeigler-Hill \& Todd Shackelford (eds.), The SAGE Handbook of Personality and Individual Differences (pp. 592628). Thousand Oakes, CA: SAGE.

We all have our time machines, don't we. Those that take us back are memories... And those that carry us forward, are dreams.

H.G. Wells, The Time Machine (1895)

The ability to perform mental time travels (MTT) constitutes a discontinuity between humans and other animals (Suddendorf \& Corballis, 1997, 2007). This absolutely unique capacity, engaging a variety of cognitive systems, with a prominent role of episodic memory, allows us "not only to go back in time, but also to foresee, plan, and shape virtually any specific future event” (Suddendorf \& Corballis, 2007, p. 299). Due to these properties, emergence of MTT was a fundamental step in our current evolutionary success. Analyzed at the level of species, the concept of MTT allows to answer the question about what is specifically human, as well as to identify underpinnings of our evolutionary success. 
However, within-species comparisons are no less important, as they allow understanding and predicting pronounced individual differences in psychological processes and behaviors.

Among a variety of dimensions that reflect individual differences in time-related features, such as chronotype (Horne \& Östberg, 1976), temporal aspects of temperament (Strelau, 1996), time perception (Wittmann, 2013), and many others, the concept of time perspective (TP) plays a particularly important role. In the present chapter we provide an overview of the current knowledge about the phenomenon of TP. We reflect on the nature of this complex construct, introduce the universe of TP dimensions, review available measurement techniques, present its nomological network, and analyze profound consequences of temporal orientations for human functioning. Finally, we propose a novel conceptualization of the phenomenon, distinguishing between state and trait TP, and reflect on possible future research pathways in the area of temporal psychology.

\section{TPs in the history of psychological science}

\subsection{The long history of time and psychology}

In its attempts to understand human functioning, psychology has been interested in homo sapiens' abilities to transcend the present and to project himself or herself mentally in time. These capacities, long considered specific to our species, were at the core of the reflections by Aristotle (third century BCE) and of Saint Augustine (third century after CE), in order to understand the deep nature of the human mind. These two philosophers thus raised fundamental questions about the existence of time, wondering whether it is situated in the world, as objective and concrete, or in the mind, as subjective and ideal.

If the question arises, it is because we become aware of its presence through the instrument intended for its measurement (notion of time passed only appears to us when reading the clock!). Unlike space, time is not directly perceived, and is thus elusive. Yet we speak of time as something we have or not, gain or lose, as a real and tangible resource. 
Where is the origin of this perception and this consciousness of an imperceptible dimension?

For Aristotle, time lies in the number and rhythm of movements in the world, and also in our perceptual ability to count these changes. Saint Augustine was the first to propose that our consciousness extends beyond the present, and that the present we perceive contains a part of past and future things. This "distended" present would then be what enables us to perceive changes and duration, and to attribute to the world a temporality that does not present itself to our senses. This difficulty in conceiving what time is time places the human mind as the fundamental condition for the recognition of time. In his Physics, Aristotle argued that time does not exist since it is composed of the past, which no longer exists, of the future, which is not yet, and of the present which is evanescent, and disappears ceaselessly (Physics, Book IV Chapters 10-14).

Scientific study of the human ability to perceive and conceive time was the topic of a chapter in one of the earliest handbooks of psychology (James, 1890). In this chapter, James synthesizes his reflections, mainly philosophical, on time perception, emphasizing that it comes from our ability to grasp our flow of consciousness, and from what he calls the "specious present," which extends beyond the instant and contains the past and the future "in perspective" (p. 375). In his view, this present is not the duration of consciousness, but the consciousness of duration. This specious present is the object of a symbolic representation, which divided it into temporal registers, and adds rhythm and order of succession, of events or experiences. Time perception is built on the basis of this representation, and no longer on the intimate consciousness of change.

The phenomenology of time consciousness, developed subsequently by Husserl (1928), or in Heidegger's (1927) reflections on "Being and Time", contribute to a definition of subjective time as each subject's relation to the environment on the basis of the psychological organization of the past, the present, and the future, allowing for the development of 
anticipation from past experiences. This emphasis on subjective time has to be distinguished from that of an objective time, which serves as the basis for the measurement of psychological phenomena (e.g., reaction time, learning and conditioning in time; Donders, 1868; Pavlov, 1927). These latter contributions approached time as an external dimension that was continuous and linear, which can be perceived (the perception of time) and measured, and then it constitutes one of the psychologically processed stimuli. As Adam (1990) noted, it is a question of studying psychological phenomena in time, more than time in psychological phenomena.

But how does the succession of perceptions in time lead to this notion of time we use when we speak of past, present, and future? For Guyau (1890) and Janet (1928), this transition from perception to symbolic representation takes place by a progressive elaboration, through the development of temporal markers and also via related semantic competences (see also Wundt, 1910). Telling stories "presentify" what is absent, and actualize in the here and now relevant elements of memories and expectations (Tolman, 1932). It is also sharing how time affects us and arouses emotions, which Minkowski (1933) calls our "feelings of time" (e.g., impatience, boredom, melancholia, anxiety). These authors refer to experiences of time indicative of a gap between time expectations and actual time perceptions. When this gap is chronic and if individual coping resources are insufficient, that can lead to "time psychopathologies" (Minkowski, 1933).

\subsection{From psychology of time to temporal psychology}

These immediate perceptions and feelings of time are gradually transformed into conceptions of time, or "temporal hypotheses" that guide our behavior (Piaget, 1937). These symbolizations are the foundations of what Piaget (1946) called "temporal horizons", which are mental spaces widened in the dimensions of time, which allow us to link present experiences with those already experienced previously and to bond them with intentions 
directed towards the future. This is also what Margaret Mead (1932) described as the 'presentification' of the past and the future, and connected with the present in what she calls, after Aall (1912), "temporal perspectives" (1932, p.57). Mead also insisted, as James did, on the anchoring of these perspectives in the present, and the fact that it is from the present that the past and the future will be retrieved. This "attention" (Mead, 1932) directed beyond the present toward the past and the future intervenes in decisions, behaviors and identity construction, and is based both on individual experiences and on collective values and social norms learned through socialization in various cultural settings.

The concept of TP was definitively established in its present meaning by Lewin, in his foundational paper, Time Perspective and Morale, published in 1942. Lewin relied on an earlier treatise by Franck (1939), where the cultural anchoring of TPs and its variations related to age, culture, or social class were emphasized. Lewin's theory of TP is grounded in his phenomenological and dynamical approach toward all psychological phenomena. In a Lewinian view, TP is a structural and a dynamical dimension of the psychological field (i.e., the constellation of different factors which influence a person's behavior at a given time), and corresponds to "the totality of the individual's views of his psychological future and psychological past existing at a given time" (Lewin, 1951, p. 75). In Lewin's view, the TP is a dimension through which the psychological field expands together with the level of reality (Lewin, 1946), and this extension allows for planification and goal-directed complex behaviors, in interdependence with the relevant past. Hence, "The setting up of goals is closely related to time perspective" (Lewin, 1942, p. 80), and also to "actions, emotions, and certainly the morale of an individual at any instant depend upon his total time perspective" ( $\mathrm{p}$. 80).

In Lewin's (1942) project of an ecological approach to understanding human behavior, he defined the TP as a construct dynamically related to the environment (a social- 
psychological definition also present in Hulett, 1944). Relying on his experiments with children, Lewin underlined how an insecure situation (such as the sudden interference of an adult in a children free play activity) may create frustration and anger by paralyzing the action by shrinking their TP. He also mentioned how goals that are too immediate or too distant may lead to dysfunctional behaviors given children's limited ability to balance present and future gains and losses in goal-related decision-making. Lewin (1942) is more of an imagined research program than a report of completed empirical studies. However, it opened a new research area, and is in this sense the foundational introduction of TP theory in psychological science. Since then, a large body of research explored differences in TP in quantitative ways using a large variety of measures.

This concise history of TP research in psychological science brings into light the continuity of the concept, despite the disparity of approaches and measures. As a construct with a Lewinian heritage, TP is a broadly defined construct, dynamically interdependent with the environment, and equally rooted in the fields of personality and social psychology. After decades of research, the ground is prepared for a more rigorous, but not less complex, definition of this crucial aspect of our daily psychological functioning.

\section{Placing TP on the map of temporal psychology}

\subsection{Defining TP with regard to temporal psychology}

TP is a hard construct to define. The earliest definition by Lewin (1951) was "the totality of the individual's views of his psychological future and psychological past existing at a given time" (p. 75) but this is slightly vague, and may relate to many aspects of time psychology. More recent definitions are not much clearer. For Zimbardo and Boyd (2008), TP is "the often non-conscious personal attitude that each of us holds towards time and the process whereby the continual flow of existence is bundled into time categories that help to give order, coherence, and meaning to our lives" (p. 51). 
Attitude towards past, present, and future, the parceling of experience in time frames, and the sense making of daily life is still a broader definition, as we will discuss in the following part. It may be of interest to contrast TP from the numerous closely related constructs. Indeed, there are many contenders: Views on the future and past may be understood as views of the future and the past (Husman \& Shell, 2008; Nurmi, 1991), closely related to anticipations (Atance \& O’Neill, 2001) and also, of memories (Tulving, 2002). In the affective tone of the time orientations one may find the constructs of pessimism/optimism (Carver, Scheier, \& Segerstrom, 2010; Chang, Maydeu-Olivares, \& D’Zurilla, 1997), anxiety (Zaleski, 1996), or regret (Gilovich, Medvec, \& Kahneman, 1998). In the present focus of the time orientations one notes sensation seeking (Zuckerman, 1971) or impulsivity (Wittmann \& Paulus, 2008).

Some definitions of TP also consider it to be separate from its contents, or from the goals towards which the motivation is directed (Vansteenkiste et al., 2004). The length of TP could easily be considered as a kind of psychological distance (Trope \& Liberman, 2003), and the relative predominance of one perspective over others may be considered as a temporal focus (Shipp, Edwards, \& Lambert, 2009) or a time orientation (DeVolder, 1979). Combining some of these various dimensions may also correspond to time styles (Usunier \& ValetteFlorence, 2007), navigating through perspectives may resemble mental time travel (Suddendorf \& Busby, 2005), and particular relations to the future may sustain time metaphors (Boroditsky, 2000). Biases in low future orientation can be considered as delay discounting (Green \& Myerson, 2004), lack of capacity to delay gratification (Mischel, Shoda \& Rodriguez, 1989), or failure to consider future consequences (Strathman, Gleicher, Boninger, \& Edwards, 1994). In addition, there are personal preferences for functioning in the morning or in the evening (chronotypes; Roenneberg, Wirz-Justice, \& Merrow, 2003), as well as differences in temporal aspects of cultural background, partly defined by long-term 
orientation (Hofstede \& Minkov, 2010) or pace of life (Levine \& Norenzayan, 1999).

As one can see, it is not an easy task to elaborate on distinctions that were not fully considered by the authors of these many constructs. All of them are partly related or overlapping/correlated with TP (see Stolarski, Fieulaine, \& van Beek, 2015, particularly the nomological table in the appendix). As memories or aspirations, anticipations and goals, and any vision of the future, both the present and the past, are in a TP. To have a "view" on these temporal elements implies having a psychological space in which they can appear, be perceived, or be activated for present meanings and decisions. TP is not its content. TP is the totality, as a dynamical structure, of the temporally marked objects that are present at one moment in one individual's or group's psychological field (as noted by Lewin, 1942). It is the temporal extension of this psychological field interdependent with the content. It may extend to include a distant object, or an object may appear and therefore extend the field. TP does not correspond to events in time, but instead to time in merely psychological events.

This structural facet of TP is associated with an affective tone related to the totality of the temporally marked objects. As a whole, views of the past, the present, or the future may result in positive or negative evaluations. This results in attitudes related to past, present, and future, which correspond to the dominant affectivity associated with each time frame. According to Wallace and Rabin (1960), TP was defined in contrast with both time perception and temporal experience. With the TP construct, time is not an object to be perceived by a passive consciousness, nor a feeling or an affect from the intrinsic individual experience. The TP construct engages the whole personality, the projection toward immediate and distant times in the past and the future, and as such, is a component of personality. Hence, TP can be contrasted from other time-related constructs using a two-dimensional space (see Figure 1), defined by a person (personality, experience) or context focus (perception, representation), and by the definition of time as an object (perceived object) or as a milieu (the environment of 
perception).

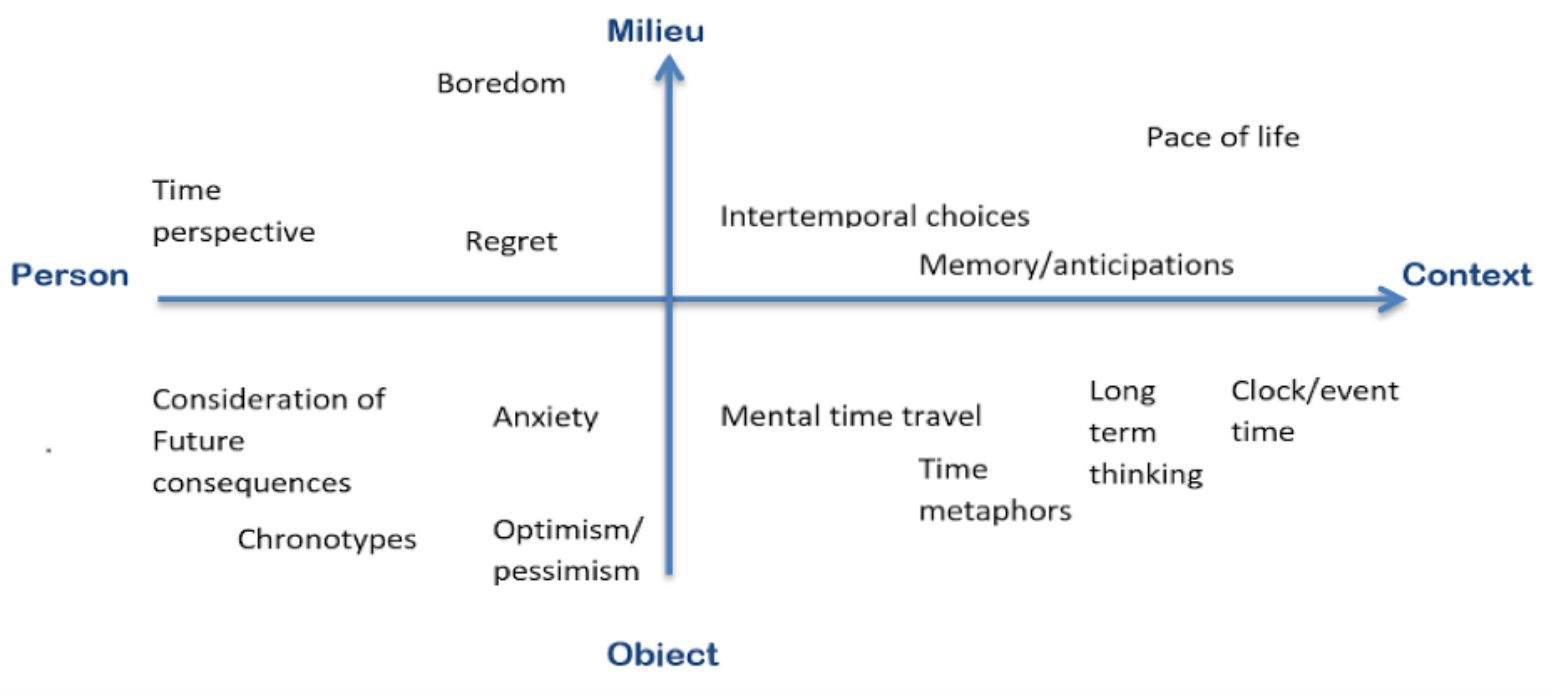

Figure 1. Two-dimensional space illustrating similarities and differences between various features of human temporal-psychological functioning.

From this model, it appears that TP is specific in its position as a person-focused construct considering time as a milieu rather than an object. This molar approach (Lewin, 1951; Wallace \& Rabin, 1960) prepared the ground for a multiplication of sub-dimensions and of variations in the definitions that create a considerable heterogeneity in research and an enduring difficulty to compare and cumulate findings.

\subsection{Measuring psychological time}

Few authors have reviewed the many measures that have been proposed to assess TP, despite the great interest of such an analysis needed for the elaboration and research uses of such measures. The most comprehensive one was proposed by Thiébaut (1997) who distinguished between measures based on projective tasks, autobiographies, stories and completion tasks, events lists, graphical techniques, attitude scales, and questionnaires or inventories. As the most commonly used instance of projective techniques, the Thematic Apperception Test (TAT; Murray, 1955) consists of showing boards containing a figurative drawing representing various and ambiguous social situations, asking the subject to tell a 
story from these boards, and isolating and codifying the temporal characteristics of the narrative as indicators of individuals' TP. In autobiographical tasks, subjects are invited to describe their past, present, and/or future personal lives, either orally or in writing, using life stories (Allport, Bruner, \& Jandorf, 1941) or autobiographies (Gillipsie \& Allport, 1955). Techniques based on stories or sentences completion (Barndt \& Johnson, 1955) consist in using a beginning of history or phrase as stimulus, from which the subjects elaborate the sequence. This elaboration may concern a complete history, the portion of a sentence from which the beginning (Nuttin, 1980), or the beginning and the ending are given (Ruiz \& Krauss, 1968). Differences in these methods are related both to the stimulus used, the complementary tasks asked of the subjects, and the way responses are coded. Motivational Induction Method (MIM; Nuttin, 1980) is among the most commonly used techniques. Events lists (Kastenbaum, 1961; Poole \& Cooney, 1987) consist in asking subjects to cite the events that come spontaneously to their mind related their past or their future. In a second step, they can be invited to localize these events in coming or past times. This second task is the main objective of the technique of pre-established events lists, asking subjects to indicate their temporal location, that is, when the event occurred or will occur.

Another set of tools brings together graphic techniques, especially line and circle tests. The line test (Cottle \& Pleck, 1969; Rappaport, Enrich, \& Wilson, 1985) consists of presenting subjects with a line from birth to death, on which they must situate the present and/or a series of events. Beyond the flat line, the life-line technique also proposes a vertical axis to capture the quality of the biographic experience (Fieulaine, 2006). The circles test (Cottle, 1968) consists of presenting subjects with three circles of different sizes, and asking them to assign a temporal register to each circle (past, present, or future) and then to arrange them according to their distance, overlap and/or order (Mello, Finan, \& Worrell, 2013). Attitudes scales are mostly based on the technique of the semantic differential (Osgood, Suci, 
\& Tannenbaum, 1957), associating time-related items with antonym adjectives presented on bipolar scales. Finally, questionnaires and inventories - which represent the most developed but also the most heterogeneous category - asks individuals to indicate their level of agreement from a list of items developed by the researcher, directly related to time, or temporally marked. Thiébaut (1997) proposed to arrange all those techniques on a continuum, defined by the level of constraint that is applied to a respondent's answers, which go from open techniques to closed ones (see Figure 2).

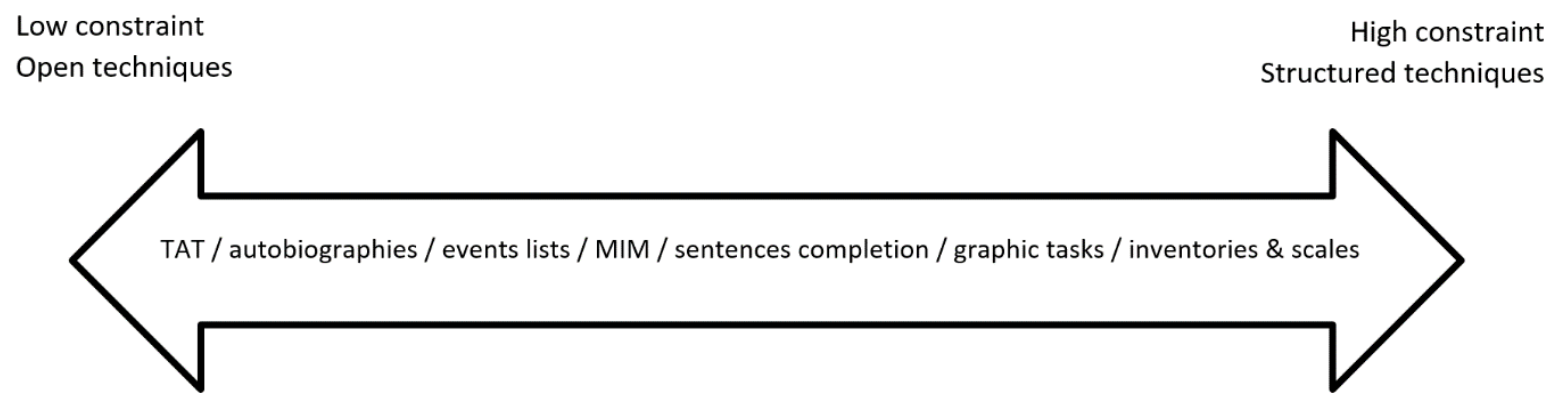

Figure 2. Constraint continuum of TP measures

Despite their more qualitative or quantitative basis, all these tools were created to propose a reliable measure of $\mathrm{TP}$, but with slightly different approaches. Content-based approaches consider that events, goals or stories are indicative of the length, the orientation, and the affective tone of TP. In some cases, authors assert that those psychological objects actually are the TP (Lens, Paixao, Herrera, \& Grobler, 2012). Also, a specific postulate is that objective time (the past or coming days, months or years) in which subjects localize the events or goals could be a good indicator of the psychological distance, density, and coherence attached with a particular TP. In graphic techniques like Circle Tests, TP is explored more independently of its content, and is considered as a context in which events can take place. In attitude scales and inventories, the item's content is designed to refer to a more or less global view on temporally marked objects, and therefore to the situational or dispositional level of TP. 
Table 1. TP measures developed before 1999.

\begin{tabular}{|c|c|}
\hline Instrument name & Author(s) \\
\hline Méthode d'induction motivationnelle & Nuttin (1980) \\
\hline Sentence Completion test relating to self-concept & Coleman, Herzberg, \& Morris (1977) \\
\hline Affective Events test & Vella (1977) \\
\hline Wishes concerning improbable events & Israeli (1932) \\
\hline World Problems Questionnaire & Zaleski, Chewinski, \& Lens (1994) \\
\hline Prediction of future events & Anderson, Spielman, \& Bargh (1992) \\
\hline Events test & Lessing (1972); Wallace (1956) \\
\hline Future events test & Stein, Sarbin, \& Kulik (1963) \\
\hline Future openness & Heinberg (1963) \\
\hline Time reference inventory & Rose \& Albers (1965) \\
\hline Time perspective questionnaire & Thog (1962) \\
\hline Time attitude scale & Nuttin (1980) \\
\hline Temporal semantic space & Menhamen (1971) \\
\hline Time metaphor test & Krupp \& Garbin (1965) \\
\hline Future time perspective questionnaire & Fingerman \& Perlmutter (1995) \\
\hline Future anxiety scale & Zaleski (1994) \\
\hline The optimism/pessimism scale & Dember \& Brooks (1989) \\
\hline Time Structure questionnaire & Bond \& Feather (1988) \\
\hline
\end{tabular}


Future time perspective test

Future time orientation scale

Inventory of temporal experience

The Ricks-Epley-Wessman temporal experience questionnaire

Temporal orientation

Temporal integration inventory

Temporal orientation questionnaire

Time attitude scale

Considerations of Future Consequences (CFC Scale)
Daltrey (1982)

Gjesme (1979)

Yonge (1973)

Wessman (1973)

Bradley \& Freed (1971)

Melges et al. (1970)

Wulf (1969)

Calabresi \& Cohen (1968)

Strathman, Gleicher, Boninger, \& Edwards (1994)

Note. For all references, see Thiebaut (1997).

One can more fully appreciate the extreme dispersion of measurement tools (see Table 1) before the introduction of the Zimbardo Time Perspective Inventory (ZTPI; Zimbardo \& Boyd, 1999). The ZTPI has been widely adopted as a new standard measure, and now is one of the few powerfully validated scales at the global level. Nowadays, only a limited number of scales have demonstrated validity, and capture different aspects of the experience of time. Among them, it is worth to mention the Temporal Focus Scale (Shipp, Edwards, \& Lambert, 2009), that assesses cognitive engagement with the past, present and future, the Time Styles Questionnaire (Usunier \& Valette-Florence, 2007) which captures individual time orientations, and the Consideration of Future Consequences Scale (Strathman et al., 1994). 


\section{TP universe: theory and measurement}

\subsection{The Zimbardo and Boyd's model of TP}

Initial studies on temporal perspectives focused mainly on only one dimension, namely, the future. Such an approach has been applied by Wallace (1956), Lens (1986), and Zaleski (1994), among many others. People with low future orientation were considered to be present-oriented, and these two orientations were treated as two opposite ends of one dimension. In their seminal work, Zimbardo and Boyd (1999) challenged these conceptualizations of TPs, pointing out that "focusing on but one dimension, they fail to provide assessments of the relative strengths of the other dimensions within individual temporal profiles. Moreover, they assume, incorrectly, that scoring low on a scale of future orientation is equivalent to scoring high on a scale of present orientation or that scoring low on a measure of the present is equivalent to being future oriented" (p. 1272). Those authors attempted to develop a novel self-report measure of TPs that would allow the measurement of a whole spectrum of temporal perspectives. After a number of preliminary studies, including repeated factor analyses, the authors established a five-factor solution that proved stable across different samples.

The final tool, the ZTPI, consists of five distinct and at most moderately correlated dimensions: Past-Negative, Past-Positive, Present-Hedonistic, Present-Fatalistic, and Future. In parallel, the authors developed a single-scale supplement to the basic version of the ZTPI the Future-Transcendental Scale (Boyd \& Zimbardo, 1997). Later developments of the TP theory resulted in identifying additional temporal dimensions. The idea of Expanded-Present (Zimbardo, Sword, \& Sword, 2012), initially theoretical, found its reflection in novel presentrelated concepts that sought to measure positive aspects of the present focus (e.g., PresentEudaimonic; Vowinckel, Westerhof, Bohlmeijer, \& Webster, 2015, or Carpe Diem TP; Sobol-Kwapińska, 2013). Swedish researchers provided evidence for distinguishing between 
Future-Positive and Future-Negative (Carelli, Wiberg, \& Wiberg, 2013). Researchers continue to analyze the ways in which people concentrate on particular time horizons, and proposing novel temporal perspectives, among which the concept of Prenatal-Past TP seems the most intriguing. A scheme providing an overview of the TP dimensions is provided in Figure 3. We believe that this overview, albeit simplified and probably incomplete, may serve as a useful frame for considering the complexity of the TP universe.

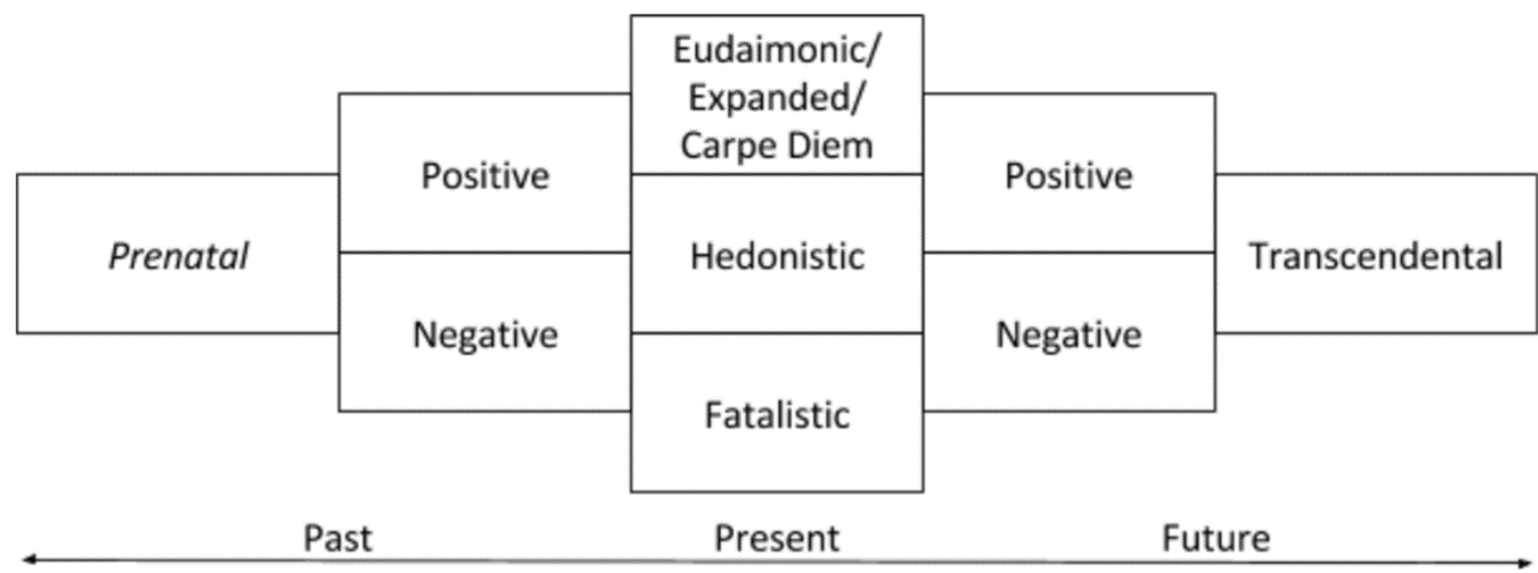

Figure 3. Graphical conceptualization of the TP universe.

Individual past is present in our perceptions and thoughts thanks to our memory processes, mainly those related to episodic memory (see Tulving, 2002). Zimbardo and Boyd (1999) introduced two past-oriented dimensions, differing in emotional valence. PastNegative "reflects a generally negative, aversive view of the past" (p. 1274) and "suggest trauma, pain, and regret" (p. 1275). It contains two subdomains: one related to trauma and one reflected in regret (Sircova \& Osin, 2016). Past-Positive "reflects a warm, sentimental attitude towards the past" (Zimbardo \& Boyd, 1999, p. 1275), and "is characterized by a glowing, nostalgic, positive construction of the past" (p. 1275). Also, two subfactors were identified: positive memories and tradition/nostalgia (Sircova \& Osin, 2016). Albeit seemingly opposite, the two past temporal perspectives are not just two ends of a single dimension, and remain only slightly correlated (see sections 4.1.1. and 4.1.2 for further discussion of past TPs). 
The 1999 TP model comprised two present dimensions. Present-Fatalistic "reveals a fatalistic, helpless, and hopeless attitude toward the future and life" (p. 1275), and "reflects the absence of a focused TP. It lacks the goal focus of future-oriented individuals, the emphasis on excitement of hedonists, and the nostalgia or bitterness of those high on the two past factors. Instead, it reveals a belief that the future is predestined and uninfluenced by individual actions, whereas the present must be borne with resignation because humans are at the whimsical mercy of "fate"' (p. 1278). Thus, the core of this dimension is a set of beliefs rather than a clear present-oriented temporal focus. Being "stuck" in the present is in this case a byproduct of a lack of the sense of control or absence of clear motivations to focus on any temporal horizon. Subfactors of fatalism and irresponsibility could be distinguished within Present-Fatalistic (Sircova \& Osin, 2016). Present-Hedonistic "is characterized by an orientation toward present enjoyment, pleasure, and excitement, without sacrifices today for rewards tomorrow" (Zimbardo \& Boyd, 1999, p. 1278) and "reflects a hedonistic, risk-taking, "devil may care" attitude towards time and life" (p. 1275). Therefore, the dimension reflects what has been earlier interpreted as a lack of Future TP. This, however, does not seem to be true: Future and Present-Hedonistic are only weakly intercorrelated (Zimbardo \& Boyd, 1999) and elevated levels of these perspectives may co-occur within a balanced TP profile. Sircova and Osin (2016) identified three major components of Present-Hedonistic: 1) impulsivity/risk taking, 2) excitement seeking, and 3) process orientation. The nature of this TP is somewhat ambivalent, as although impulsivity clearly leads to negative consequences, the process orientation remains an important aspect of well-being (see also section 4.1.3).

Researchers applying the original TP model have noticed that it lacks an unambiguously positive present dimension. Moreover, it is not obvious whether the two existing present dimensions indeed reflect a present perspective: Present-Fatalistic may be as well interpreted as a lack of any particular temporal focus or a sort of temporal inertia, 
whereas Present-Hedonistic is actually expressed in seeking immediate pleasure (i.e., reflects a short-term future focus) and that is where its motivational role origins. This resulted in the development of novel present-positive scales. Introduced by Sobol-Kwapińska (2013), CarpeDiem temporal orientation "is understood as the total focus of attention on the 'here and now,' accompanied by a perception of the value of every moment as unique, the only one of its kind" (Sobol-Kwapińska, Jankowski, \& Przepiórka, 2016, p. 113). It contains two major aspects: focusing attention on what is happening "here and now" and a conviction about the value of every moment of life. Another notable approach was proposed by Vowinckel and colleagues (2015), who combined two present-oriented positive psychology concepts Mindfulness and Flow - and proposed a novel dimension labeled Present-Eudaimonic. The most recent conception of a holistic type of present orientation is the Expanded Present created by Zimbardo, McDermott, and Zimbardo (in press). This scale is distinct from present hedonism and present fatalism, although they share some common variance. Impressive is the correlation cluster of relationships between the expanded present and four traditional dimensions with shared elements of conceptual meaning: openness, mindfulness, life satisfaction and emotional health. The researchers hope that this new scale will encourage interest in the importance of espousing an expanded present TP, which can help people experience time as more expansive, promote acts of kindness, privilege experience over possession and garner a sense of personal well-being.

The Future dimension, introduced by Zimbardo and Boyd (1999) "is characterized by planning for and achievement of future goals" (p. 1278) and "reflects a general future orientation" (p. 1275). Two subfactors of this TP may be distinguished - discipline and planning (Sircova \& Osin, 2016). Zimbardo and Boyd (1999) predicted that future research may reveal "a more complex set of future factors" (p. 1283). Indeed, some more recent works from Swedish researchers (Carelli, Wiberg, \& Wiberg, 2011) resulted in development of S- 
ZTPI, an extended version of the ZTPI questionnaire with two separate future factors: FuturePositive (similar to the original Future dimension) and Future-Negative which "involves thinking about the future with worry, anticipating negative outcomes" (Carelli, Wiberg, \& Wiberg, 2011, p. 221). Similar concepts could be found in earlier research in temporal psychology (e.g., see Zaleski's [1996] concept of Future Anxiety).

Boyd and Zimbardo (1997) presented their ideas about partitioning the psychological future into a pre- and post-death time frame, the latter transcending life and living. The Transcendental-Future TP "postulated to be distinct and separate from the traditional future, encompasses the period of time from the imagined death of the physical body to infinity (...). [It] may contain goals such as reunion with deceased loved ones, eternal life, reincarnation, the avoidance of eternal damnation, and the elimination of current poverty, pain, suffering and shame" (Boyd \& Zimbardo, 1997, p. 36). This concept extended the TP universe with a beyond-death dimension; however, a problem with this dimension is that it neglects the content of transcendental belief. For instance, a difference between having a vision of a vengeful vs. a merciful God may be much greater than between having high vs. low levels of transcendental perspective (see van Beek \& Kairys, 2015).

The concept of Prenatal TP is a novel idea proposed by van Beek (2012) and further theoretically developed by van Beek and Kairys (2015). While discussing the issue of FutureTranscendental, they posed a question of how the role of time can exist before the actual birth of a child. Where and who was the child before it was born, and how does this affect one's current life? This "before-birth" time horizon is a part of the context the person is born into. Obviously, sometimes that context is implicit and maybe even unconscious, but in some religious traditions it is manifest and of utmost importance. As we have seen, mostly in nonWestern religions and from other than linear TPs, people can be motivated by trans-individual aspects, like forefathers or rebirth. The cyclic nature of this way of looking upon time and 
temporality makes a specific after-life time horizon even recurrent. Even from a Western perspective, the ideas, dreams, beliefs, wishes, and anxieties of the parents and environment may affect the development of the infant, which has been reflected in the work of Jung (1936/1980) which introduced the idea of a primitive, collective unconscious. Beliefs about being a wanted or unwanted child, the proud or embarrassing history of their family or nation, or even the nature of mankind (being planned and created by God vs. being a product of evolutionary processes) may underpin one's identity, self-concept, and self-esteem and, indirectly, become a vital factor influencing undertaken actions. Development of a measure of the prenatal TP(s) could provide some interesting, novel possibilities in TP research, and it would enrich TP theory to address this as well at the conceptual level (van Beek \& Kairys, 2015).

The above list of temporal orientations is obviously open. The example of the novel present orientations shows that further developments in the area, but also in broadly understood psychological science, could bring novel conceptual ideas that could further expand the TP universe.

\subsection{The ideal temporal profile: Balanced TP}

Beyond the several dimensions that compose TP, Zimbardo and Boyd (1999) proposed an approach that accounted for the interactions between TP sub-dimensions, and therefore the temporal profiles that can better describe individuals' TP as a whole. Earlier, Lennings, Burns, and Cooney (1998) described different TP profiles based on work by Cottle (1969) who isolated three distinct temporal profiles, related to broad personality dimensions, and several other authors suggested the existence of profiles of TP, at the individual or cultural levels.

In the field of TP research, the profile issue was addressed mainly to discover the most adaptive one (Boniwell \& Zimbardo, 2004; for analysis of other TP profiles see Boniwell et 
al., 2010). Such an optimal profile has been labeled balanced TP (BTP; Zimbardo \& Boyd, 1999). Zimbardo and Boyd (1999) defined BTP as "the mental ability to switch effectively among TPs depending on task features, situational considerations, and personal resources, rather than be biased towards a specific TP that is not adaptive across situations" (p. 1285). The definition emphasizes a process nature of BTP: a dynamic switching between particular time horizons constitutes the essence of BTP. The initial way in which balance was illustrated by Zimbardo and Boyd (2008) was simply an 'optimal' TP profile, with a high score on PastPositive, moderately high scores for Future and Present-Hedonistic, and low scores for PastNegative and Present-Fatalistic. Based on these assumptions and distribution of ZTPI scores in a large US sample, hypothetically optimal raw scores on each ZTPI dimensions were identified (see Figure 4).

The concept of BTP has always been described in terms of adaptation mechanisms (Boniwell \& Zimbardo, 2004; Zimbardo \& Boyd, 1999); however, for almost a decade the claims regarding its regulatory role were based mainly on correlations of the ZTPI dimensions with other adaptive and maladaptive dimensions. Drake and colleagues (2008) were the first to empirically analyze TP profiles. They proposed a cut-off approach to distinguish between balanced and unbalanced profiles. From that moment numerous studies demonstrated the wide-ranging power of BTP in predicting many beneficial outcomes. Drake's approach, however, has been criticized and gave way to other, more valid and conceptually justified methods to assess temporal balance (see Stolarski, Wiberg, \& Osin, 2015, for an in-depth analysis of BTP assessment). Among them, Deviation from the BTP (DBTP) coefficient (Stolarski, Bitner, \& Zimbardo, 2011) - which is based on the optimal points suggested by Zimbardo and Boyd (2008) - gained the greatest popularity among researchers because it provides a continuous, normally distributed ZTPI-based indicator of balance, and revealed the highest convergent validity in comparison to cut-off approach and hierarchical cluster analysis 
(Zhang, Howell, \& Stolarski, 2013). Of course, the question arises whether these raw 'optimal' points are truly optimal, however a number of comparisons with other 'candidate' points (e.g., extremely high points on positive dimensions and extremely low on the negative ones, or points analogically derived from other samples, both US and foreign), for some reason have always been inferior to the original ones. A revised version of the DBTP with Future-Negative dimension included was recently introduced by Rönnlund, Åström, and Carelli (2017).

BTP proved to be strongly associated with a variety of well-being indicators (Boniwell et al., 2010; Drake et al., 2008; Zhang, Howell, \& Stolarski, 2013), predicting as much as $40 \%$ of their variance. Temporal balance not only predicts well-being over and above extraversion and neuroticism, but it also moderates effects of those traits on subjective wellbeing, such that in highly balanced individuals, the effects of the personality traits on wellbeing are no longer significant (Stolarski, 2016). BTP is associated with such variables as emotional intelligence (Stolarski, Bitner, \& Zimbardo, 2011), mindfulness (Drake et al., 2008, Stolarski, Vowinckel, Jankowski, \& Zajenkowski, 2016), wisdom (Webster, Bohlmeijer, \& Westerhof, 2014), as well as ego-integrity (Webster, 2016). Recent research showed that BTP is related to temperamental traits of Briskness and (inversely) Emotional Reactivity (Stolarski \& Cyniak-Cieciura, 2016), and to executive functions (Zajenkowski, Stolarski, Witowska, et al., 2016), providing evidence for its key role in switching processes, and low-impulsive, intentional regulation of one's momentary temporal focus. These results are in-line with results showing that BTP partly results from processes of temporal metacognition (Stolarski \& Witowska, in press).

As a consequence of these regulative processes, individuals with highly balanced temporal perspectives experience more positive moods (Stolarski et al., 2014), lower stress and anxiety (Papastamatelou, Unger, Giotakos, \& Athanasiadou, 2015), and lesser PTSD after 
traumatic experience (Stolarski \& Cyniak-Cieciura, 2016). While performing a demanding cognitive task, they experience higher task engagement, lower worry, and less distress, which in turn, results in higher levels of performance (Zajenkowski, Stolarski, Maciantowicz, et al., 2016). They also feel time in a different way, experiencing slower passage of time, lower time pressure, lower boredom, and less routine (Wittmann et al., 2015). They remain more satisfied with their romantic relationships (Stolarski, Wojtkowska, \& Kwiecińska, 2016), make more healthy leisure choices (Garcia \& Ruiz, 2015) and are more ethical in their business dealings (Unger, Yan, \& Busch, in press). Olivera-Figueroa and colleagues (2015) showed that BTP predicts cortisol dynamics in healthy individuals. Guo, Chen, and Feng (2017) found that temporal balance was associated with gray matter volume and resting-state functional connectivity between brain regions which are commonly considered as core nodes of the default mode network that is known to be involved in many functions, including episodic and autobiographical memory, theory of mind, and imagining the future. 


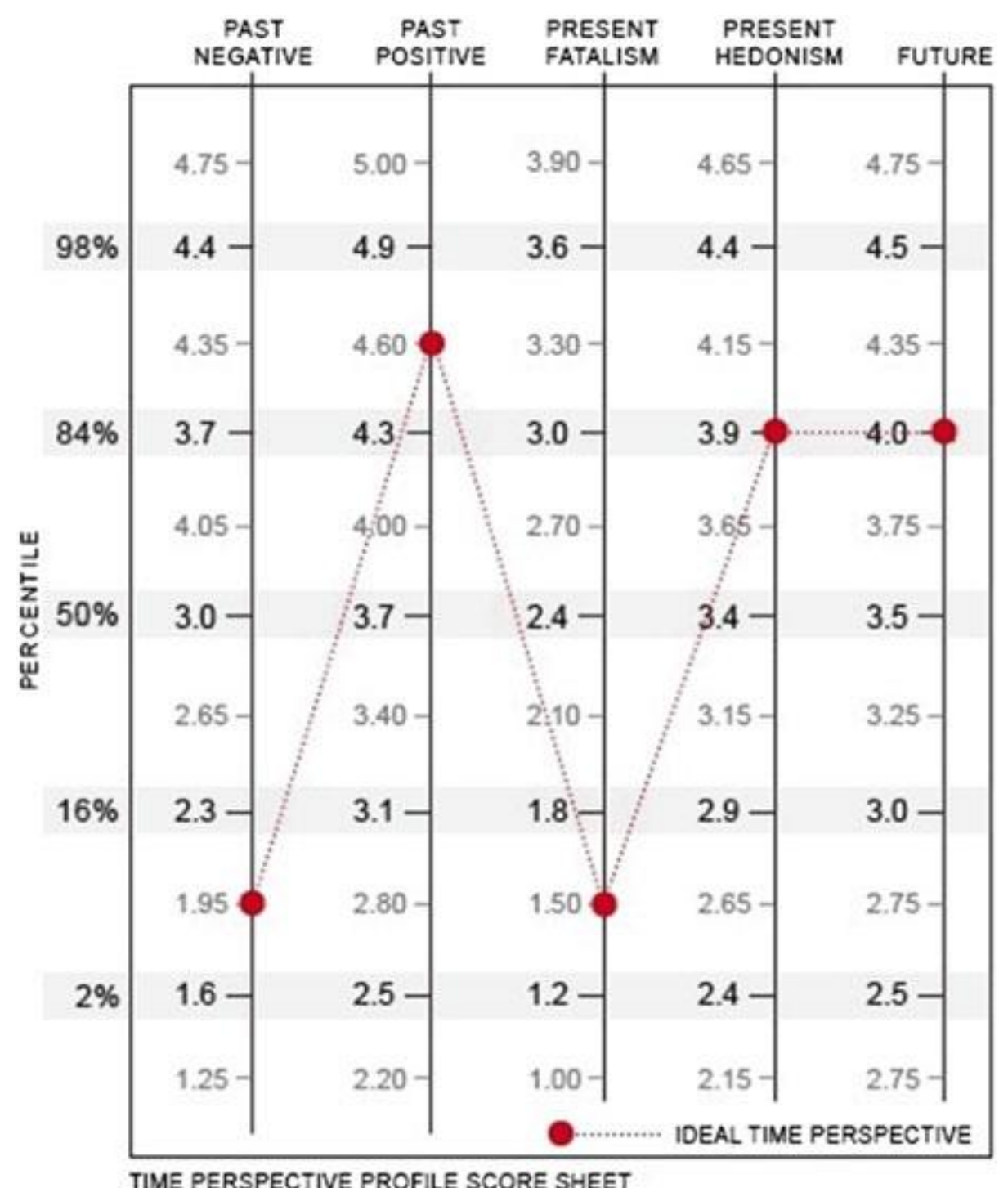

Figure 4. Graphical illustration of the BTP profile (taken from www.timeparadox.com/surveys/).

The overview of the TP universe presented above is of course selective and by necessity incomplete. However, we believe that it provides a good starting point for a reader who was unfamiliar with the idea of TP. It also provides a basic frame of reference for the further, deepened analyses of nomological networks and consequences of TP dimensions, presented in the following sections of the present chapter.

\subsection{The current measures of TPs}

The issue of measurement is naturally one of the central challenges for personality science. As in the case of personality, the majority of researchers within the field of 
psychological time have relied on self-report measures. In the present section we provide a brief overview of the leading psychometric approaches to measure individual differences within the area of psychological time. Moreover we signal potential future directions in TP measurement.

\subsubsection{The ZTPI family of measures}

The ZTPI that was developed by Zimbardo and Boyd, was officially introduced in 1999, however studies using working versions of the scale had been conducted since the mideighties (see Gonzalez \& Zimbardo, 1985; Zimbardo \& Gonzalez, 1984). The final 1999 version of the ZTPI consists of 56 items that are divided into five empirically distinguished dimensions: Past-Negative, Past-Positive, Present-Hedonistic, Present-Fatalistic and Future. The scale has been translated and validated in numerous cultures, with over 20 adaptations in various languages (see Sircova et al., 2014). Carelli, Wiberg, and Wiberg (2011) proposed an extended 64-item Swedish version of the ZTPI, with a novel Future-Negative dimension. The ZTPI is often accompanied by the Transcendental-Future Time Perspective Inventory (Boyd \& Zimbardo, 1997).

Across more than two decades of research, many modified versions of the ZTPI have been developed. D’Alessio, Guarino, Pascalis, and Zimbardo (2003) introduced the Stanford Time Perspective Inventory - Short Form which is a 22-item Italian version of the measure that contains three subscales: Present-Hedonistic, Present-Fatalistic, and Future. Sircova and colleagues (2014) compared the structural equivalence of the ZTPI across 26 samples from 24 countries $(N=12,200)$, and proposed a 36-item long version valid for cross-cultural analyses (still recommending the full-ZTPI for within-culture studies). Brief versions were developed in France (15 items; Fieulaine \& Martinez, 2010), USA (15 items; Zhang, Howell \& Bowerman, 2013), Australia (25 items; Homewood, Mahmut, Meiser, Taylor, \& Wakefield, 2010), Israel (20 items; Orkibi, 2015) and the Czech Republic (15/18 items; Koštál et al., 
2016). The latter scale seem particularly valuable because it consists of items that were selected based on Sircova et al. (2014) cross-cultural analyses; moreover, it also contains additional Future-Negative subscale.

\subsubsection{Mello and Worrell's Time Inventory}

Mello and Worrell $(2007,2015)$ have developed several instruments to assess TP dimensions, including time attitudes, time orientation, time relation, and time frequency. Time attitudes refer to positive and negative feelings one has toward each time period. The Time Attitude Scale (TAS) consists of 30 items with six subscales: past positive, past negative, present positive, present negative, future positive, and future negative. The TAS has yielded a valid structure and reliable scores in adolescent samples from Germany and America (Worrell, Mello, \& Buhl, 2013), New Zealand (Alansari et al., 2013), and the UK (McKay et al., 2015). Most recently, the TAS was shown to be an appropriate instrument with young, middle, and older adults (Mello et al., 2016). Time attitudes have been meaningfully associated with educational and psychological outcomes (Andretta et al., 2014) and with alcohol use in adolescents (McKay et al., 2014).

Time orientation and time relation are both assessed with single-item scales that measure an emphasis and a perceived connection among the time periods, respectively. The Time Orientation Scale (Mello et al., 2013) includes several sets of circles that vary in size with larger circles indicating more importance. Participants are asked to select one figure among several that vary in size. Studies with adolescents have shown that participants who emphasize more time periods also have higher self-esteem and academic achievement and lower risk-taking (Mello et al., 2013). The Time Relation Scale (Mello et al., 2013) measures the perceived connections among the time periods with a series of circles that vary in overlap. Participants are asked to select one figure among four that differ from unrelated to overlapping (i.e., Venn diagram). Studies with adolescents have shown that perceiving time 
periods to be related is associated with higher self-esteem and academic achievement as well as lower risk-taking (Mello et al., 2013). The last dimension of TP assessed is time frequency, which refers to the rate of thinking about the past, present, and future.

\subsubsection{Webster's Balanced Time Perspective Scale}

Another measure of TP has been developed by Webster (2011). His Balanced Time Perspective Scale (BTPS) consists of two subscales - Past and Future with each containing 14 items. According to Webster (2011), four temporal clusters can be distinguished based on its results - time restricted (low scores on both dimensions), time expansive/balanced (high on both), futurists (high Future, low Past), and reminiscers (low Future, high Past). Individuals in the time expansive category manifest increased happiness, well-being, wisdom, mental health, and self-esteem compared to the remaining groups (Webster, 2011; Webster, Bohlmeijer, \& Westerhof, 2014; Webster \& Ma, 2013). Recently, Vowinckel and colleagues (2017) proposed to complement the model with a Present-Eudaimonic scale, and showed that BTP that was measured using the expanded BTPS may be even more predictive of mental health than ZTPI-based indicators of balance. We believe that the novel dimension could prove a valuable addition not only to BTPS, but also to ZTPI.

\section{TPs' nomological networks and clinical applications}

\subsection{The nomological network}

One of the most effective ways to explore the true nature of a given psychological construct is to establish its nomological network. Associations with well-established individual differences, such as classic personality dimensions or abilities, allow researchers to uncover the most important features of any psychological trait or process, hypothesize about its underpinnings, and predict its consequences. In the present section we analyze TP dimensions by discussing their joint variance with major constructs of individual differences, including personality traits (see Table 2), cognitive abilities, and other personal 
characteristics.

Table 2. Weighted average correlation coefficients between five basic dimensions of TP and the Big Five traits

\begin{tabular}{lccccc}
\hline & \multicolumn{5}{c}{ The Big Five } \\
\cline { 2 - 6 } & $\mathrm{N}$ & $\mathrm{E}$ & $\mathrm{O}$ & $\mathrm{A}$ & $\mathrm{C}$ \\
\hline Past-Negative & $\mathbf{. 4 8}$ & $\mathbf{- . 2 4}$ & .07 & -.12 & -.19 \\
Past-Positive & -.08 & .18 & -.09 & $\mathbf{. 2 4}$ & .13 \\
Present-Hedonistic & .08 & $\mathbf{. 3 0}$ & $\mathbf{. 2 3}$ & .02 & -.18 \\
Present-Fatalistic & $\mathbf{. 2 6}$ & -.10 & -.15 & -.07 & $\mathbf{- . 2 5}$ \\
Future & -.07 & .10 & .03 & .14 & $\mathbf{. 6 0}$ \\
\hline
\end{tabular}

Note. The coefficients are from Kairys \& Liniauskaite (2015); total N=2728. Relationships accounting for at least $5 \%$ of shared variance are given in bold.

\subsubsection{Past-Negative}

According to a meta-analysis conducted by Kairys and Liniauskaite (2015), Past-

Negative displays a robust association with neuroticism, almost reaching the value of .50 .

Past-Negative was also powerfully related to Negative Affect (e.g., Desmyter \& De Raedt, 2012), trait depression (e.g., Carelli \& Wiberg, 2012), trait anxiety (e.g., Anangostopoulos \& Griva, 2012), and Tense Arousal (Stolarski et al., 2014), confirming that the dimension is powerfully loaded with negative emotionality. Inverse relationships with Past-Negative were reported for such variables as Positive Affect (Desmyter \& De Raedt, 2012), life satisfaction (Zhang \& Howell, 2012), mindfulness (Drake et al., 2008), emotional intelligence (Stolarski, Bitner, \& Zimbardo, 2011), and various features of psychological well-being (Boniwell et al., 2010; Sircova \& Mitina, 2008) but these associations were typically weaker than those obtained for indicators of negative affectivity.

Past-Negative was also associated with Machiavellianism and Psychopathy (Birkás \& Csathó, 2015) but not with Narcissism, which seems logical, given that it is also related to low self-esteem (Anagnostopoulos \& Griva, 2012). This result sheds some light on the 'dark nature' of Past-Negative: although this TP may indicate tendencies to manipulate other people and behave in an impulsive, antisocial way, it does not necessarily reflect grandiosity or 
egotism. This issue was further investigated by Zajenkowski, Witowska, Maciantowicz, and Malesza (2016) who showed that Past-Negative is associated with vulnerable narcissism, but not with grandiose narcissism. Some interesting insights regarding a rather complex nature of Past-Negative come from research on aggression (Stolarski, Zajenkowski, \& Zajenkowska, 2016). In their study, Past-Negative was related to verbal aggression, however after including two mediators from the emotional level (i.e., anger and hostility) the direction of this association reversed from positive to negative, revealing that beside clearly active components, expressed in elevated anger or impulsivity, Past-Negative also has a passive, depressive component that may even inhibit some negative behavioral tendencies.

Finally, it is worth emphasizing, that despite its evident negative emotionality loadings, Past-Negative is not reducible to negative emotionality. Numerous studies revealed incremental validity of Past-Negative over and above indicators of negative affectivity. For instance, Zhang and Howell (2011) showed that Past-Negative predicted life satisfaction after controlling for the Big Five, whereas Stolarski and Matthews (2016) replicated this result and broadened it with analogic analyses predicting transient mood. EFA-based discriminant validity analyses (see Zimbardo \& Boyd, 1999) showed that although Past-Negative was substantially associated with depression, it remained a distinct factor. Studies concerning psychopathological symptoms revealed that remaining "stuck" in the negative past is characteristic not only for depressed individuals, but also for those manifesting elevated levels of anxiety (McKay, Cole, \& Andretta, 2016) and PTSD (Holman \& Silver, 1998, 2005).

\subsubsection{Past-Positive}

Although one may have assumed that Past-Positive is simply the opposite end of PastNegative dimension, a brief look at intercorrelations between TP scales shows that this is not the case. The two past ZTPI dimensions are rather weakly associated, sharing only around 4$6 \%$ of joint variance (e.g., Sircova et al., 2015; Zimbardo \& Boyd, 1999). Thus, any 
combination of levels of these two TPs is possible. From our unpublished analyses of frequencies of particular configurations of these two dimensions, we may conclude that around $9 \%$ of a huge U.S. population scored low (1st tercile) on both TPs, whereas about $8 \%$ obtained high (3rd tercile) scores on both. This is important, as it significantly changes our way of thinking about these TPs; it also justifies conducting analyses of interactions between the past dimensions that may provide some illuminative insights into the nature of TP-related phenomena.

Past-Positive dimension does not manifest any particularly strong connections to personality traits. However, a modest positive correlation with agreeableness is probably worth noting, as it taps the warm, positive attitude toward other people that characterizes individuals scoring high on Past-Positive. Past-Positive predicts various aspects of autobiographical memory, including more emotionally intense, sensorially rich, and linguistically coherent memories, a tendency to foster connections between the past and present through more frequent reminiscing, as well as a false belief that remembered events actually occurred (Ely \& Mercurio, 2011). It also indicates a sort of both retrospective and prospective memory bias: individuals scoring high on this dimension tend to recollect past moods as more energetic than they actually were; a similar effect may be observed with regard to anticipations of future moods (Stolarski et al., 2014).

Past-Positive indicates a warm, sentimental attitude toward the past, but also appears to reflect some self-regulation abilities that include reconstruction of past memories in order to cope effectively with past experiences, even the traumatic ones. The later feature, although not expressed explicitly in the definition (see section 3.1), is supported by the results of a reasonable number of empirical studies. For instance, Past-Positive turned out to be the only TP dimension significantly associated with all branches of ability-based emotional intelligence (Stolarski, Bitner, \& Zimbardo, 2011). This result may reflect either an important 
role of this orientation in emotional regulation or a key role of emotional abilities in development of the positive view of the past. Furthermore, analyses conducted within a novel concept of temporal metacognition showed that Past-Positive is positively related to each of the three distinguished aspects of temporal metacognition (Stolarski \& Witowska, in press; see section 6.1.2). Finally, recent research showed that Past-Positive may attenuate the maladaptive effects of Past-Negative on aggression (Stolarski, Zajenkowski, \& Zajenkowska, 2016). The latter two results provide further support for a notable role of Past-Positive in fundamental self-regulation processes.

\subsubsection{Present-Hedonistic}

Present-Hedonistic remains the most ambivalent dimension in the whole TP universe. On the one hand, it is positively associated with extraversion and agreeableness which suggests a marked sociability component. That finding is supported by results providing evidence for links between Present-Hedonistic and positive social relations with others (Sircova \& Mitina, 2008) as well as trait emotional intelligence (Stolarski, Bitner, \& Zimbardo, 2011) . It also (modestly) predicts higher levels of various aspects of well-being (Boniwell et al., 2010; Shipp, Edwards, \& Lambert, 2009), curiosity (Kashdan, Rose, \& Fincham, 2004), and more positive moods (particularly energetic arousal; Stolarski et al., 2014). On the other hand, as we already mentioned above, Present-Hedonistic clearly has robust impulsivity (MacKillop et al., 2006) and excitement seeking components which leads to pronounced positive associations with aggression (Stolarski, Zajenkowski, \& Zajenkowska, 2016), substance use and abuse (Fieulaine \& Martinez, 2010; Keough, Zimbardo, \& Boyd, 1999), pathological gambling (Hodgins \& Engel, 2002), and risky driving (Zimbardo, Keough, \& Boyd, 1997), as well as risky health behaviors (Henson et al., 2006). At a more general level, risk taking seems to be one of the central features of this dimension, as PresentHedonistic proved to be the only domain-unspecific predictor of risk taking, among TPs and 
the Big Five traits (Jochemczyk et al., 2016).

Present-Hedonistic is positively associated with extraversion and openness to experience, which emphasizes the elevated level of approach motivation in individuals high in Present-Hedonistic. This is reflected in its positive associations with both sensation and novelty seeking (Zimbardo \& Boyd, 1999). This TP is also associated with 'eveningness' (Stolarski, Ledzińska, \& Matthews, 2013), which is consistent with both present-hedonists' pronounced sociability, and, on the other hand, with their elevated impulsivity and low selfcontrol. This pattern of results also seems consistent with the pattern of associations between Present-Hedonistic and aggression. Although it predicts both verbal and physical aggression, this association is mediated via anger, but not hostility (Stolarski, Zajenkowski, \& Zajenkowska, 2016), which again highlights the impulsive character of this dimension. In the clinical context, elevated levels of Present-Hedonistic seem typical for mania (Gruber, Cunningham, Kirkland, \& Hay, 2012). Finally, Present-Hedonism proved to be associated with a whole spectrum of dimensions reflecting fast life history strategy (see also section 4.3.), such as frequent sexual behavior and more sexual partners (Rothspan \& Read, 1996) or sociosexuality (Stolarski et al., 2017).

\subsubsection{Present-Fatalistic}

Present-Fatalistic dimension is positively associated with neuroticism, depression, and anxiety, and negatively associated with conscientiousness (Anagnastatopoulos \& Griva, 2012) or lower mood (Stolarski et al., 2014). Although it clearly contains a negative emotionality component, its loading is definitely weaker than in the case of Past-Negative. Instead, external locus of control remains the core feature of this dimension (Shipp et al., 2009). The prepotent sense of fatalism leads individuals scoring high on Present-Fatalistic dimension to increased suicidal ideation (Laghi, Baiocco, D’Alessio, \& Gurrieri, 2009), avoidant procrastination (Ferrari \& Díaz-Morales, 2007) and lack of planning for the future (Baumann \& Odum, 
2012). Actually, present-fatalists typically neither have a clear vision of future self (McElwee \& Haugh, 2009) nor do they consider future consequences of their behaviors (Zimbardo \& Boyd, 1999).

Behavioral consequences of habitual taking of this temporal perspective remain severe. Pathological gambling (Hodgins \& Engel, 2002), tobacco, alcohol, and drug use (Daugherty \& Brase, 2010), less frequent seat belt and condom use (Henson et al., 2005), and lower pro-environmental behaviors (Corral-Verdugo, Fraijo-Sing \& Pinheiro, 2006), are just a few examples of the consequences of Present-Fatalistic orientation. Increased frustration resulting from the sense of helplessness results in elevated frustration of present fatalists, which, in turn, results in higher experienced anger and hostility, ultimately leading to increased aggressive behaviors (Stolarski et al., 2016).

\subsubsection{Future/Future-Positive}

Future TP has often been described in terms of a fundamental motivational dimension (e.g., Nuttin, 1964, 1985). Studies conducted within Zimbardo and Boyd's (1999) conceptual framework strongly corroborate this claim, showing that individuals with elevated levels of Future are more curious and exploring (Kashdan et al., 2004), learn more and receive higher grades (Zimbardo \& Boyd, 1999), obtain higher levels of education and receive higher income (Holman \& Silver, 2005; Shores \& Scott, 2007), and experience higher levels of energetic arousal, which may be treated as an affective marker of motivation (Stolarski et al., 2014; Stolarski \& Matthews, 2016). The exuberant motivational nature of this perspective is also clearly visible in its robust positive association with conscientiousness. Unlike present fatalists, people with elevated Future perspective have more internal locus of control (Shipp et al., 2009). Future-oriented individuals live healthy lives: they exercise more and use seatbelts more often (Daugherty \& Brase, 2010), frequently undergo cervical cancer screening (Ronancio, Ward, \& Fernandez, 2014), are more effective in quitting smoking (Kovač \& Rise, 
2007), they use psycho-stimulants less frequently than peers (Henson et al., 2006), manifest higher medication adherence (Sansbury et al., 2014), and are more concerned about their health (Milfont et al., 2008). They are also more proactive (Anagnostopoulos \& Griva, 2012), manifest higher levels of self-control (Milfont \& Schwarzenthal, 2014), and procrastinate less (Ferrari \& Díaz-Morales, 2007). Their conscientious and proactive attitude results in elevated pro-environmental behaviors (Milfont, Wilson, \& Diniz, 2012), as well as increased longevity (Daugherty \& Brase, 2010).

Particularly interesting results regard the role of Future orientation in intentionbehavior consistency. Future-oriented individuals exhibit particularly high intention-behavior consistency (Van Ittersum, 2012), which is manifested in multiple life areas, including quitting smoking (Kovač \& Rise, 2007), weight control (Vinkers, Adriaanse, \& de Ridder, 2013), academic functioning (Horstmashof \& Zimitat, 2007), or even participation in longitudinal research (Harber, Zimbardo, \& Boyd, 2003).

Another important line of research focuses on the role of future orientation in the context of coping with traumatic experiences. Future perspective was related to lower distress long after various traumatic events (Holman \& Silver, 1998), predicted using active coping strategies and adjustment after 9/11 terrorist attacks (Holman \& Silver, 2005). The crucial role of Future TP was also demonstrated in other studies revealing its associations with a variety of posttraumatic reactions (e.g., Martz \& Livneh, 2007).

\subsubsection{Other TP dimensions}

There is much less data regarding nomological networks of the remaining TP dimensions (i.e., those that were not included in the original ZTPI questionnaire). FutureTranscendental (Boyd \& Zimbardo, 1997), albeit quite often mentioned and cited in articles on temporal perspectives, is rarely studied. Differences in this perspective are associated with religiosity (Ortuño, Paixão, \& Janeiro, 2011), but this result should be treated rather as an 
indicator of the scale's validity. It is also rather independent from personality. Levels of Future-Transcendental, however, clearly differ between religious persuasions, with highest scores obtained by Protestants, and the lowest by Judaism followers (Boyd \& Zimbardo, 1997). Vásquez, Difabio de Anglat and Noriega Biggio (2016) showed that individuals scoring high on Future-Transcendental scale are more motivated to sacrifice their own needs in order to protect and support other people; they are also less egocentric and less individualistic. These researchers also found that such individuals are more keen to take responsibility for their own actions, and accept established norms. Their research is one of the few exceptions showing significant associations of Transcendental-Future with other variables. In a study by Seema, Sircova, and Baltin (2014), Future-Transcendental was unrelated to well-being, mindfulness, and self-esteem. The authors argued that the scale measures belief in an afterlife, but not a TP. We agree that another TP scale should be developed that consists of items asking how often people imagine themselves in a transcendental future context and if these thoughts are positive or negative.

Future-Negative (Carelli, Wiberg, \& Wiberg, 2011) dimension is robustly associated with Past-Negative dimension (correlations are as high as .68). This robust covariance results from the huge negative affectivity component in both dimensions which is clearly visible when we take a look at their associations with neuroticism (Stolarski \& Matthews, 2016) or anxiety (Åström et al., 2014). Stolarski and Matthews (2016) showed that Future-Negative is the strongest correlate of negative moods and decreased well-being from the entire TP universe, and its influences exceed those obtained for the Big Five traits, including neuroticism and extraversion (see Rönnlund, Åström, \& Carelli, 2017, for further evidence for the robust effects of Future-Negative on well-being). In another study, Future-Negative was associated with more avoidant and dependent decision-making styles, as well as with lower confidence in interpersonal relationships, and more elevated need for social approval, 
discomfort with closeness, and preoccupation with relationships (Molinari et al., 2016). These effects may have important consequences for functioning in romantic relationships, as FutureNegative has been shown to play a significant inhibitory role in sexual satisfaction in heterosexual couples (Stolarski, Wojtkowska, \& Kwiecińska, 2016).

The idea of positive present dimensions has also recently appeared in the TP literature as a response to a lack of an indicator of clearly positive focus of a present orientation in the original Zimbardo and Boyd (1999) model. The idea of the existence of a positive, mindful present appeared in some works by Zimbardo (e.g., the concept of expanded or holistic present; Zimbardo, Sword, \& Sword, 2012), but for a long time it lacked empirical operationalization. Sobol-Kwapińska (2009) showed that unlike hedonism and fatalism, active present time orientation was associated with greater satisfaction with life and with more effective achievement of goals. Her further research found that Carpe Diem orientation which is how she labeled the positive form of present focus - is associated with higher selfesteem and greater optimism (Sobol-Kwapińska \& Jankowski, 2016), higher positive affect, lower neuroticism, and less negative ways of perceiving and metaphorizing time (SobolKwapińska, 2013). Interestingly, Carpe Diem was shown to be a separate construct from mindfulness: whereas mindfulness is mainly concerned with the form of awareness of the present, Carpe Diem is concerned with its content. The interaction of these two dimensions was demonstrated to have a particularly positive effect on satisfaction of basic psychological needs (Sobol-Kwapińska et al., 2016).

Another approach was proposed by Vowinckel, Westerhof, Bohlmeijer, and Webster (2017), who introduced a Present-Eudaimonic scale, referring to conceptual frameworks of mindfulness and flow theories. They demonstrated that the novel dimension (obviously different from the one proposed by Sobol-Kwapińska), predicts a robust amount of mental health over and above traditional ZTPI dimensions. It also proved substantially associated 
with mindfulness and flow proneness, which reflects this new construct's nature.

Further research using these several present scale is needed to uncover the actual nature and functions of these novel dimensions in the TP universe. However, hitherto results seem promising and provide sufficient rationale to use them along with the now traditional basic scales.

\subsection{Practical applications of TPs}

From these theoretical, and empirical foundations, a number of practical applications have emerged in many different domains. For a recent complete summary of many of them, we refer readers to our TP encyclopedia (see Stolarski, Fieulaine, and van Beek, 2015, parts IV and V). The most successful examples of the applied psychology of TP are to be found in financial management, and in TP-based PTSD therapy, as well as in TP coaching.

\subsubsection{TP and financial health}

As we have noted earlier, BTP people have been shown to have a greater all around sense of well-being, better mental health, and are likely to be financially secure. Following up on this last attribute, It has been shown that it is possible to predict which individuals will make financially successful decisions while avoiding seemingly attractive, but deceptive investment appeals by primarily knowing their TP - much more so than by knowing their financial acumen, or understanding of accounting principles (Rabinovich, Morton, \& Postmes, 2010). Two New York businessmen wanted to develop a corporation that helped people make wise choices in credit card selections, as well as in choosing which banks to invest money in, and what kind of loans that were being proposed are most appropriate for them. They invited Zimbardo to be their consultant in developing measures that integrated ZTPI TP profiles of their clients with many other measures of financial knowledge and financial health. Their income is derived in part by commissions they receive from those banks, credit card companies, and loan agencies, as well as from their clients. 
The company is known as Magnify Money (www.MagnifyMoney.com). Their research revealed the importance of a BTP in financial health of their most successful clients. Those who were past oriented were risk aversive; present hedonists took attractive but highly risky deals; future oriented investors often waited for more evidence before investing, thus missing rare opportunities. Revealing such biases to their clients enabled them to make wiser, more rewarding financial decisions (Zimbardo, Clements, \& Karimzad, 2016). Recently, Magnify Money was acquired by LendingTree LLC for a total consideration of nearly $\$ 40$ million USD. This is a great adaptation of TP ideas that leads to financial wealth for the team originators, as well as financial health for their clients.

\subsubsection{TP-based therapy}

TP is not just about making decisions, but also a practical philosophy that will enrich one's life journey, and along the way help deal with some personal mental problems. A new form of TP therapy was developed by Richard and Rosemary Sword in collaboration with Zimbardo. A summary of their application of practical principles of TP theory to treat clients who were suffering from PTSD is detailed in The Time Cure (Zimbardo, Sword, \& Sword, 2012). Most clients were military veterans but some, particularly women, were suffering from sexual abuse, and some had survived fatal car accidents. This variation of cognitive modification therapy teaches clients how to become 'unstuck' from their often horrific, past negative experience, to build on past positive memories, begin planning for a hope-filled future, while enjoying more fully each day's chosen hedonistic pleasures (see also Sword, Sword, Brunskill, \& Zimbardo, 2014). The Time Cure narrative reveals a great deal of success reducing the symptoms of PTSD, anxiety, and depression with these benefits persisting for more than 4 years for all 30 veteran clients (see www.TimePerspectiveTherapy.org).

TP has also been effectively applied in therapeutic contexts other than PTSD. For instance, van Beek, Kerkhof, and Beekman (2009) developed a group training for patients 
with suicidal thoughts that is easy to apply in clinical settings as an addition to regular treatment, whereas Kazakina (2015) highlighted how TP theory could be incorporated to various psychotherapeutic approaches, including cognitive, behavioral, psychodynamic and existential therapies.

\subsubsection{TP coaching}

Another particularly valuable application comes from within the area of positive psychology. Referring to basic ideas of TP theory, particularly the concept of BTP, Boniwell (2005) proposed to use it as a theoretical framework for coaching and other developmental interventions. In further works, basing both on the most effective time-related interventions in positive psychology, such as positive portfolio (Fredrickson, 2009) or funeral service (Frisch, 2006), and some brand new TP-based techniques, Boniwell, Osin, and Sircova (2014) proposed a step-by-step guide for practitioners on how to start with TP coaching: from performing initial diagnostics, to distinguishing problems associated with excessive reliance on particular time frames, and providing practical tools that can help individuals to overcome the negative consequences associated with them. Coaching practice has often lacked theoretical background, and it seems that TP theory may provide comprehensive and useful conceptual frames for effective interventions supporting personal development.

\subsubsection{Other fields of TP applications}

Beyond these clinical practices based on the TP theory, a dynamical field of applied research emerged in relation to the growing interest in how the temporal lens can help to understand and tackle critical contemporary issues. The two most developed areas are without doubt those on health prevention and promotion (Boyd \& Zimbardo, 2005) and the climate change crisis (Milfont \& Demarque, 2015). Those two fields are in strong need of new perspectives to understand better how and why people have difficulty to change their behaviors to their own health and well-being and the good of our planet. TP research 
demonstrated that temporal biases could explain a part of people's inaction to take care of the environment despite the perceivable consequences of using an individual car or wasting natural resources, or of individuals' inability to change their behavior even when they know the likely consequences for their future health. These two challenges both address the issue of thinking beyond the here and now, and to consider the future consequences of our present behaviors. In both cases, orientation toward the future was established as a driver for sustainable and health behaviors, whereas present orientation (mainly hedonistic) was observed as reducing those behaviors. However, the results were often more complex, as was the case for substance use as an example (Apostolidis, Fieulaine, Simonin \& Rolland, 2006; Fieulaine \& Martinez, 2010). In some case, a more external explanation have been suggested, in which the impact of TP on intentions or behaviors is a result of an interaction between individuals temporal profiles and the temporal framing of the information to promote sustainable or health behaviors (Martinez \& Fieulaine, 2015). The default framing of "enduring costs in the present for future benefits" could be influential in dissuading presentoriented populations to perform the promoted behaviors (Orbell \& Hagger, 2006). Hence, a temporal tailoring of information and campaigns in accordance with target populations' of different dominant TPs is one of the actual application of TP research. These applications are only at their early stage. Insights from TP research would be useful and impactful for many other fields like public policies, urban planning, design, new technologies use and abuse, security challenges in the face of terrorism, or education and parenting.

\section{Challenges for TP theory and research}

\subsection{Toward a reconceptualization of TP: A state, a trait, and a meta-cognition}

Despite of the apparent process focus and dynamical nature of TP that is emphasized in its seminal definition, "the (...) process whereby the continual flows of personal and social experiences are assigned to temporal categories" (Zimbardo \& Boyd, 1999, p. 1271), the 
construct was introduced and operationalized through a measure that assesses stable, individual differences in time orientation and time attitudes - the ZTPI. This suggests the evident need for clarification of what TP really is: whether it is a process or a set of stable personality-like traits, indicating what Zimbardo and Boyd (1999) labeled "response styles". In the next part of our analysis we focus directly on resolving this ambiguity and providing a novel, precise definition(s) of TP.

Researchers often ignore the above inconsistency, assuming that TP is what the ZTPI measures. In fact, even those who notice this discrepancy usually limit their studies to establishing correlations between ZTPI scales and constructs of their interest. This implies a tacit agreement that $\mathrm{TP}$ is rather a set of relatively stable dispositions rather than a dynamic process or a changing state. We agree that this practical simplification is clearly a result of a difficulty of measuring situational dynamics in temporal framing, as well as of the natural cognitive heuristic known as fundamental attribution error (Ross, 1977) but it does not excuse simplifications in interpreting the obtained results which is unfortunately commonplace in much TP research.

\subsubsection{State vs. Trait TPs}

We believe that TP should be considered both as a state, when analyzed as a momentary directing attention on a given time horizon (the past, the present, or the future) within the process of continuous framing of present experiences, and as a trait, when understood as a stable, habitual tendency to remain focused on one of the three temporal areas. Momentary, transient ("state") temporal focus remains under powerful influences of situational factors (e.g., a party will likely foster a focus on the present, a coaching session will lead to a focus on the future, a funeral will lead to a focus on the past), whereas a frequently taken perspective, especially if reinforced by cultural and education influences, may result in relatively stable biases toward one or more time horizons (Stolarski, 2016; 
Zimbardo \& Boyd, 1999, 2008), which then may be treated as individual-difference dimensions, or, simply speaking, as a personality trait. To clarify the existing TP definition(s) we propose to explicitly distinguish between state-TP and trait-TP.

- Trait TPs are stable pre-dispositional and dispositional tendencies to remain chronically oriented and manifest stable attitudes toward one or another of the three time horizons: the past, the present, or the future. In other words, the term "trait-TP" refers to relatively stable individual differences in habitual use of a particular time frame (orientation-level), combined with a specific attitude component (e.g., positive vs. negative). As such, trait-TP becomes a part of broadly understood personality.

- State TP is a momentary focus on and attitude toward a time horizon (the past, the present, or the future) in a given situation. This momentary TP is then not only a product of contemporary situation, but emerges from the interaction between the situation and stable tendencies that are reflected in trait-TP levels.

The interplay between state- and trait-TPs is illustrated in Figure 5. We decided to present the TP dynamics within the frames of the classic Lewin's equation (see Shoda, 2004), which states that Behavior is a function of Person and Situation interactions: $\mathrm{B}=f(\mathrm{P}, \mathrm{E})$. This allowed us to illustrate the issue within a broader context (i.e., to show a broad mechanism in which TP influences behavior) as well as to take into account some interesting reciprocal mechanisms in these dynamics. 


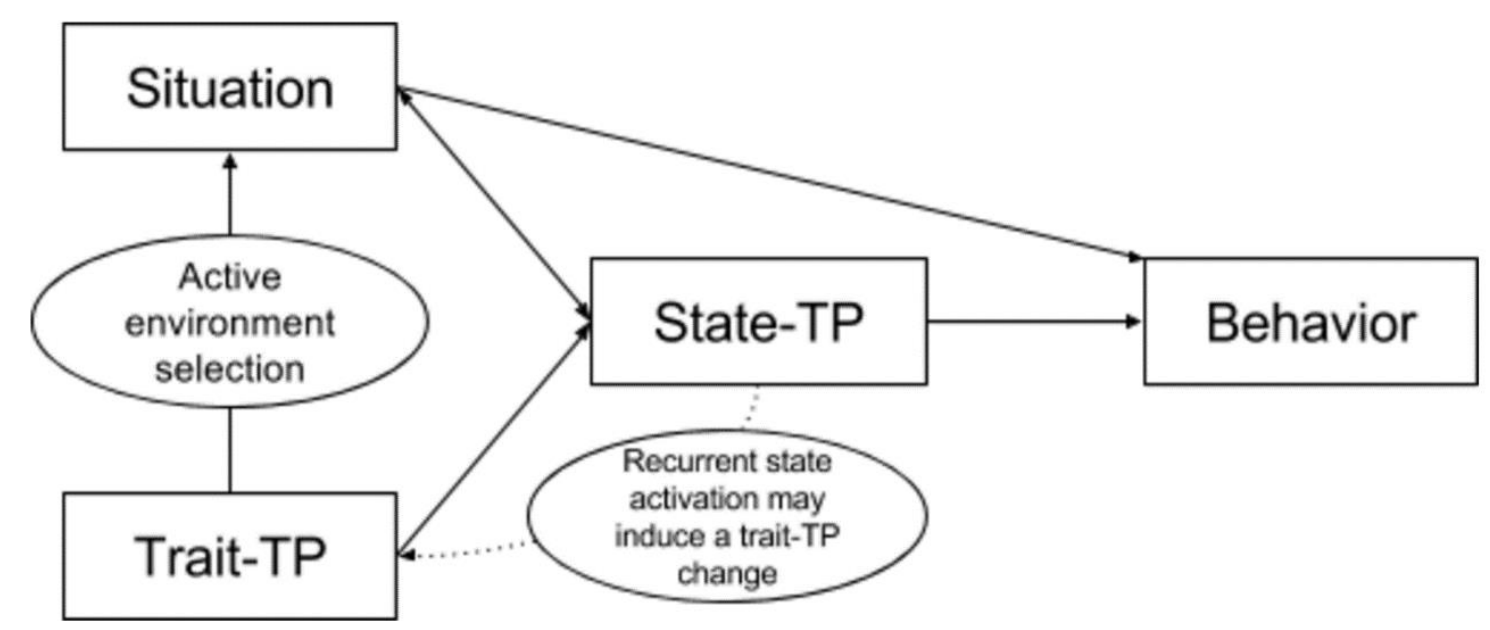

Figure 5. The interplay of Trait-TP and Situation in determining individual behavior.

First, it should be noted that momentary temporal focus (state-TP) is the product of an interplay between stable personal tendencies to focus on given temporal horizon and situational features. Let us consider a case of David, a highly present-oriented individual, working in a small company. David may focus on his future horizon when forced by his workmates to develop a work plan for a forthcoming year, but his hedonic motives will likely be still present and his ideas for the schedule will probably include more leisure time than that of his less present-oriented counterparts.

Another important element of the graph concerns the process of environment selection. When David takes his free time, he usually spends it shopping, and avoids going to the theatre: he intentionally selects the environment that allows him to behave in a way that is more consistent with his dominant TP (see García \& Ruiz, 2015). Thus, we believe that when contextual factors are not marked, one's momentary TP results mainly from their dispositional TP.

In contrast, when situational factors are predominant, one's dispositions become marginal, just as in the case of dramatic alterations in TP that occurred during the Stanford Prison Experiment (Zimbardo, Haney, Banks, \& Jaffe, 1973). When present at a funeral, 
David takes a past-perspective, even if this temporal horizon is not frequently activated in his stream of consciousness. Furthermore, we believe that frequent activations of a given temporal horizon may influence individual tendencies to take a given TP (the dotted line in Figure 5). This is how cultural and educational experiences may shape one's TP profile (see Zimbardo \& Boyd, 2008, as well as section 6.1.3), and this is the reason why TP-based positive psychology interventions may prove effective (cf. Boniwell \& Osin, 2015; see section 5.2.3).

The right part of Figure 5 reflects behavioral consequences of momentary temporal focus. David is keen to have sex on the first date because his elevated level of presenthedonism resulted in active representations of a sex-related pleasure in his mind. Of course such fantasies may be triggered or fostered by a presence of an attractive girl in the backseat of his car. It is worth noting here, that there is no direct link between trait-TP and behavior: Dispositional features always act via currently activated state-TP, and only currently "active" TP may influence our actual behaviors.

\subsubsection{Metacognitive processes in temporal framing: Not as determined as one might think}

The dynamics of temporal perspectives illustrated above may bring a conclusion that people are "doomed" or "determined" by their dispositional features and situational constraints. Such conclusion could be also derived from early works by Zimbardo and Boyd (1999) who emphasized that TPs are usually unconscious, and thus their influence typically takes place without any self-awareness. However, people may in fact become aware of their own TPs, both on the level of transient states and dispositional biases (see Zimbardo \& Boyd, 2008) and consciously and purposefully 'use' them, depending on situational and personal goals and motives, in order to maximize their own effectiveness and satisfaction (Boniwell \& Zimbardo, 2004). Balanced TP provides stable bases for such an effective, intentional 
switching between particular time horizons, as it makes the 'adaptive' time horizons easily accessible for an individual, but it remains unresolved whether the optimal profile is a sufficient or only a necessary condition for this temporal plasticity.

One recent conceptualization (Stolarski \& Witowska, in press) implies that balanced TP stems from complex cognitive (see Zajenkowski, Stolarski, Witowska, et al., 2016) and metacognitive processes that allow restraint from taking maladaptive TPs, and to wisely juggle the adaptive ones. Stolarski and Witowska (2017) empirically identified three components of temporal metacognition: Metacognitive Temporal Control, Goal-oriented Temporal Interconnectedness, and Cognitive Reconstruction of the Past. They showed that each of these dimensions uniquely contributes to BTP. Although further studies regarding this novel construct are necessary, there is already a body of solid research offering initial evidence that conscious self-regulation in temporal framing does exist, and that it influences various aspects of well-being via balancing one's own temporal perspectives.

\subsubsection{A brief reflection on the actual nature and origins of $T P$}

Based on hitherto theoretical considerations and a growing body of empirical results, we have noticed that TP, on the trait level, has a lot in common with cognitive styles (i.e., habitual ways in which people individual differences in the way people perceive, think, solve problems, learn, and relate to others; Witkin, Moore, Goodenough, \& Cox, 1977). In the case of TP, the style reflects individual tendencies, or biases, to focus on a particular time horizon (time orientation component), in a particular way (time attitude component). The attitudinal or affective valence component suggests that limiting TP to the area of cognitive functioning is not necessarily right, and brings the construct closer to personality/temperament dimensions. Therefore, perhaps TP should be treated as a personality style: the organizing principle that represents the orderly arrangement of all personal attributes, thoughts, feelings, attitudes, behaviors, and coping mechanisms (Oldham \& Morris, 1995). This somewhat audacious 
conclusion would result in viewing TP as a much broader concept than it has been treated before. However, it would also allow to explain the prepotent power of TP dimensions in predicting various affective, cognitive, and behavioral outcomes (Stolarski, Fieulaine, \& van Beek, 2015; Zimbardo \& Boyd, 2008), as well as the fact that TP is markedly associated with many personality traits (e.g., the Big Five), but it cannot be limited to these traits (see the studies of the construct incremental validity, section 6.2).

Originating from the situationist approach, Zimbardo and Boyd (1999, 2008) suggested that individual differences in TP result mainly from environmental factors, including family influences, education, or culture. How are these social and cultural experiences shaping individuals' TPs? If a large body of research demonstrated the link between TP profiles and socioeconomic status (e.g. Cottle, Howard, \& Pleck, 1969; Fieulaine \& Apostolidis, 2015; Lamm, Schmidt, \& Trommsdorff, 1976; LeShan, 1952; O’Rand \& Ellis, 1974; Peetsma 2000) or cultures (e.g., Bonger, 1972; Meade, 1971; Shannon, 1975; Sircova et al., 2015), the process by which a disposition and personality-related construct can be influenced by such broad contexts remains unclear. An approach we label as «material» insists on the concrete barriers or positive challenges people encounter in their life conditions that trigger one TP or another. Material deprivation, scarcity, financial stress, job loss, or insecurity are in this case objective constraints that limit individuals' capacity to envision the future with confidence or to perceive their life as continuous and coherent. In these contexts, TPs may be limited by necessity of adaptation, leading to a focus on the present, or to a focus on the past in a ruminating attitude. When the future is too uncertain, intentions can be projected in the past, and expressed through regrets and counterfactual thinking. Another approach could be labeled as «culturalist», as these works focus on the process through which a particular TP is transmitted by socialization and acculturation. Differential temporal socializations were observed since Leshan (1952), by which the temporalities of social groups 
are endorsed by members progressively. Parental practices for example can reflect particular time attitudes and orientation, and the child will conform and identify with it. Or a particular language style may facilitate or encourage some temporal orientations, and influence individuals through language interactions. These two approaches depict how broad contexts may be influential on individuals' TPs, and the rationale of a dispositional definition, at the interaction of personality and contexts.

This situationist standpoint, however, needs to be supplemented with the dispositional approach. The first law of behavioral genetics states that all human behavioral traits are heritable (Turkheimer, 2000), thus TPs also have to be, to some extent, heritable. Although we are not aware of any behavioral genetic studies of TPs completed to date, marked associations between strongly heritable (Oniszczenko et al., 2003) temperaments and TP dimensions (e.g., Stolarski \& Cyniak-Cieciura, 2016), suggest that at least some of the latter (i.e., the more 'temperamentally-loaded' ones such as Present-Hedonistic or Past-Negative) should have a marked genetic component. Zimbardo's claim that we are all born present hedonists, and we may become future oriented (Zimbardo \& Boyd, 2008), highlights only one side of the coin: although all healthy infants are indeed powerfully motivated by hedonic drives, we may observe robust individual differences in this area since the earliest life phases (cf. Gartstein \& Rothbart, 2003). Therefore, as in the case of personality traits, TPs result from the interaction between innate tendencies and various aspects of individual, social, and cultural experiences. The tendencies include, for instance, traits associated with negative affectivity or the need for stimulation (Zimbardo \& Boyd, 1999).

Following the distinction proposed by McAdams (see McAdams \& Olson, 2010, for a review), the development of personality could be analyzed at three different levels: 1) dispositional traits, 2) characteristic adaptations, and 3) life stories. Unlike typical personality traits (e.g., the Big Five) which represent only the first level, TPs seem to consist of elements 
representing each of the three levels. TPs obviously have the dispositional component, which we have already emphasized, and which is manifested in their covariance with the Big Five but they also contain the two remaining levels. First, temporal focus can be considered as an adaptation mechanism, both at the transient/state level (mainly via the process of switching between temporal horizons in response to changing situational demands; Boniwell \& Zimbardo, 2004), and at an evolutionary level. The latter process seems particularly interesting, as some TPs seem to be central features of two alternative types of evolutionary adaptation (i.e., slow vs. fast life history strategy; Dunkel \& Kruger, 2015).

Life History Theory is an evolutionary theory which predicts that personality traits should cluster in a non-random way as adaptations to solve adaptive tasks in response to the stability or harshness of socioecological conditions encountered in young age. Whereas unpredictable conditions tend to produce fast strategies, more predictable environments may produce slow strategies (Kaplan \& Gangestad, 2005). A slow life history strategy is reflected in a secure attachment pattern, supportive communication patterns (Olderbak \& Figueredo, 2009), a psychological inclination for long-term strategizing (Gladden, Figueredo, \& Jacobs, 2009), and long-term mating effort and relationships. Present-Hedonistic reflects an orientation toward immediate outcomes and little concern for future consequences (Zimbardo \& Boyd, 2008) which seems to be a natural consequence of a fast life history strategy, whereas Future perspective, reflecting a pattern of behavior dominated by a striving for future goals and rewards, is typical for individuals characterized by a slow life history strategy (Dunkel \& Kruger, 2015). A reasonable body of evidence shows that these two TPs indeed remain core aspects of these two adaptation strategies (e.g., Dunkel \& Kruger, 2015; Stolarski et al., 2017); thus, TP may be treated as a characteristic adaptation. Other examples supporting the claim that TP may be also considered at this level of McAdams' model include the role of TP as a basis for coping mechanisms (Holman \& Silver, 1998), emotion regulation 
strategies (see Matthews \& Stolarski, 2015), or metacognitive beliefs (Stolarski \& Witowska, in press).

Finally, one of the core functions of TP is to "help to give order, coherence, and meaning to (...)[life] events" (Zimbardo \& Boyd, 1999, p. 1271). One's perceptions of their past, present and future constitute basic frames for the narratives that give a life a sense of unity, meaning, and purpose (McAdams, 1995) that emerge in adulthood as the most complex level of their personality. Thus, from our standpoint, trait TP appears to be a multi-level feature of broadly understood personality, and depending on approach may be treated as a complex universe of traits or a time-related personality style.

\subsection{Conclusions and future directions for TP research}

Despite the exponentially growing number of empirical studies concerning TP and related constructs, many fundamental problems remain unresolved. One of the most difficult methodological tasks refers to gaining insight into the dynamically changing temporal focus. We know a lot about consequences and correlates of trait-TPs, but we know little about the dynamic process of switching between time horizons, which remains essential for balanced TP. Taking into account the complexity of TP (its cognitive, affective, attitude dispositional components), as well as the fact that that the phenomenon is hardly separable from situational context, the task may seem unfeasible. Momentary temporal focus seems to be an elusive phenomenon, accessible only via introspective meta-reflection, and even this way of gaining insight into the process of temporal framing seems highly limited if we take into account the fact that it usually remains unconscious (Zimbardo \& Boyd, 1999). However, studies applying narrative methodology (e.g., Labov, 1997) may provide some insights into individual dynamics of TP. Recent developments in the research on neural bases of TP (Carelli \& Olsson, 2015) that identified specific brain regions activated during concentration on particular time horizons suggest that in the future tracing the dynamics of temporal focus will 
be possible using neuroimaging techniques. Finally, a team of researchers leaded by Maciej Stolarski has recently begun working on an adjective checklist assessing state-TP, which would enable tracing fluctuations in temporal focus across changing situations and conducting experimental research on TP.

While discussing more or less novel constructs within the field of personality psychology, it is always important to consider their actual novelty, following the principle of Occam's razor. In the case of TP theory the issue seems particularly relevant given that TPs include - partially or entirely - some powerful, well-established individual differences, such as anxiety (in Future-Negative), external locus of control (in Present-Fatalistic), or conscientiousness (in Future-Positive). This apparent overlap naturally leads to a question of whether TPs are not just old wine poured into new bottles, or a new cocktail of old wines. A powerful response comes from studies of the incremental validity of TP. TP researchers are increasingly aware of the need to show that temporal dimensions not only predict important behavioral of affective outcomes, but also that the effects do not simply result from their covariance with established individual differences. Such studies have provided evidence that TP is not reducible to and predict solid amount of various outcomes over and above basic personality dimensions (e.g., Daugherty \& Brase, 2010; Ely \& Mercurio, 2011; Stolarski \& Matthews, 2016; Zhang \& Howell, 2011).

Another vital issue regards the eclectic nature of TPs. As we already noted above, TP is a complex phenomenon, comprising cognitive and affective components, both conscious and unconscious processes, related to personality, affect, and attitudes. It is then impossible to ascribe TP to a single area of psychology. This exposes the concept to accusations of excessive conceptual extent. Although we understand such doubts, we are convinced that it remains rather a strength than a weakness of the TP theory, because it provides a unique chance for a synthesis in the era of fragmentation in contemporary psychology (cf. Drob, 
2003). Although this phenomenon can be interpreted positively and could be stimulating for the development of the discipline (e.g., Bower, 1993), the unceasing lack of meta-theoretical synthesis makes it difficult to approach human nature in a comprehensive, holistic way. Time is a basic - albeit elusive and often hidden (Hall, 1966) - dimension of our reality. Could TP be also considered as a basic, psychological dimension, even more basic than traditional personality traits? Even if the answer is negative, we believe that TP theory could provide a framework for a comprehensive analysis of human behavior in the context of time and a conceptual hub, linking various areas of behavioral sciences and stimulating research that exceeds borders of sub-disciplines of psychology.

Lastly, as far as TP was defined as a situationally determined dimension of personality, one could reasonably expect to find studies that establish changes in TP following particular situations, and experimental study designs, allowing for statements about causal relations between the situations and TP. Unfortunately, only a few authors have conducted these sorts of studies. Savickas (1997) developed a program to help people build a careeroriented TP, and Marko and Savickas (1998) demonstrated that such a program could improve the feeling of continuity between past and future as well as a sense of optimism toward the future. In a similar approach, Hall and Fong (2003) designed an intervention program to develop consideration for long-term benefits of physical activity, that increase physical activity in participants even 6 months later. In some related field of research, hypothetical scenarios are used to induce temporal distance (Trope \& Liberman, 2003) or horizons (Carstensen, Isaacowitz, \& Charles, 1999).

Despite these several attempts, the need remains to explore how situations can influence individuals' or group TPs, using field and experimental studies. In the same socialpsychological approach, much remains to be done to understand how situations and persons interact, and how the temporal fit or unfit can help in understanding perceptions, experiences, 
and behaviors. In this aim, the inclusion of findings from construal level theory of psychological distance (Trope \& Liberman, 2010) into the TP field of research may constitute a fruitful future research avenue. This theory has many insights to share concerning how situations induce a particular psychological distance (including temporal distance), and may benefit from the dispositional approach developed in the TP field, in order to better understand when, and for whom an situationally induced temporal distance may change or influence perceptions, decisions and behaviors (Maglio, Trope, \& Liberman, 2015). 


\section{References}

Aall, A. (1912). Die Beteutung der Zeitperspektive bei der Einprägung fur die Dauer der Bedüchtnisbilder. In: F. Schumann (Ed.), Bericht iiber den V. Kongress fur experimentelle Psychologie (pp.237-241). Leipzig: Barth..

Adam, B. E. (1990). Time and social theory. Cambridge, MA: Polity Press.

Alansari, M., Worrell, F. C., Rubie-Davies, C., \& Webber, M. (2013). Adolescent Time Attitude Scale (ATAS) scores and academic outcomes in secondary school females in New Zealand. International Journal of Quantitative Research in Education, 1, 251274.

Allport, G. W., Bruner, J. S., \& Jandorf, E. M. (1941). Personality under social catastrophe: Ninety life-histories of the nazi revolution. Journal of Personality, 10(1), 1-22.

Anagnostopoulos, F., \& Griva, F. (2012). Exploring time perspective in Greek young adults: Validation of the Zimbardo Time Perspective Inventory and relationships with mental health indicators. Social Indicators Research, 106, 41-59.

Andretta, J. R., Worrell, F. C., \& Mello, Z. R. (2014). Predicting educational outcomes and psychological wellbeing in adolescents using time attitude profiles. Psychology in the Schools, 51, 434-451.

Apostolidis, T., Fieulaine, N., Simonin, L., \& Rolland, G. (2006). Cannabis use, time perspective and risk perception: Evidence of a moderating effect. Psychology and Health, 21, 571-592.

Åström, E., Wiberg, B., Sircova, A., Wiberg, M., \& Carelli, M.G. (2014). Insights into features of anxiety through multiple aspects of psychological time. Journal of Integrative Psychology and Therapeutics, 2, 3.

Atance, C. M., \& O'Neill, D. K. (2001). Episodic future thinking. Trends in Cognitive Sciences, 5, 533-539. 
Barndt, R J., \& Johnson, D. M. (1955). Time orientation in delinquents. Journal of Abnormal and Social Psychology, 51, 343-345.

Baumann, A. A., \& Odum, A. L. (2012). Impulsivity, risk taking, and timing. Behavioural Processes, 90, 408-414.

Birkás, B., \& Csathó, Á. (2015). Size the day: The time perspectives of the Dark Triad. Personality and Individual Differences, 86, 318-320.

Bonger, L. S. (1972). A developmental study of time perception and time perspective in three cultural groups: Anglo-american, Indian-American, Mexican-american. Dissertation Abstracts International, 32, 3774-3775.

Boniwell, I. (2005). Beyond time management: How the latest research on time perspective and perceived time use can assist clients with time-related concerns. International Journal of Evidence Based Coaching and Mentoring, 3, 61-74.

Boniwell, I., \& Zimbardo, P. (2004). Balancing time perspective in pursuit of optimal functioning. In P.A. Linley, \& S. Joseph (Eds.), Positive psychology in practice (pp. 165-178). Hoboken, NJ: John Wiley \& Sons.

Boniwell, I., \& Zimbardo, P. G. (2003). Time to find the right balance. The Psychologist, 16, $129-131$.

Boniwell, I., Osin, E., \& Sircova, A. (2014). Introducing time perspective coaching: A new approach to improve time management and enhance well-being. International Journal of Evidence Based Coaching and Mentoring, 12, 24-40.

Boniwell, I., Osin, E., Linley, P. A., \& Ivanchenko, G. V. (2010). A question of balance: Time perspective and well-being in British and Russian samples. The Journal of Positive Psychology, 5, 24-40.

Boroditsky, L. (2000). Metaphoric structuring: Understanding time through spatial metaphors. Cognition, 75, 1-28. 
Boyd, J. N., \& Zimbardo, P. G. (1997). Constructing time after death: The transcendentalfuture time perspective. Time \& Society, 6, 35-54.

Boyd, J. N., \& Zimbardo, P. G. (2005). Time perspective, health, and risk taking. In A. Strahman \& J. Joireman (Eds.), Understanding behavior in the context of time: Theory, research, and applications (pp. 85-107). Mahwah, NJ: Erlbaum

Carelli, M. G., \& Olsson, C. J. (2015). Neural correlates of time perspective. In M. Stolarski, N. Fieulaine, \& W. van Beek (Eds.), Time perspective theory: Review, research and application (pp. 231-242). Cham, Switzerland: Springer International Publishing.

Carelli, M. G., \& Wiberg, B. (2012). Time out of mind: Temporal perspective in adults with ADHD. Journal of Attention Disorders, 16, 460-466.

Carelli, M. G., Wiberg, B., \& Wiberg, M. (2011). Development and construct validation of the Swedish Zimbardo Time Perspective Inventory. European Journal of Psychological Assessment, 27, 220-227.

Carver, C. S., Scheier, M. F., \& Segerstrom, S. C. (2010). Optimism. Clinical Psychology Review, 30, 879-889.

Chang, E. C., Maydeu-Olivares, A., \& D'Zurilla, T. J. (1997). Optimism and pessimism as partially independent constructs: Relationship to positive and negative affectivity and psychological well-being. Personality and Individual Differences, 23, 433-440.

Coleman, J., Herzberg, J., \& Morris, M. (1977). Identity in adolescence: Present and future self-concepts. Journal of Youth and Adolescence, 6, 63-75.

Corral-Verdugo, V., Fraijo-Sing, B., \& Pinheiro, J. Q. (2006). Sustainable behavior and time perspective: Present, past, and future orientations and their relationship with water conservation behavior. Interamerican Journal of Psychology, 40, 139-147.

Cottle, T. J. (1968). The location of experience: A manifest time orientation. Acta Psychologica, 28, 129-149. 
Cottle, T. J. (1969). Temporal correlates of the achievement value and manifest anxiety. Journal of Counseling and Clinical Psychology, 5, 541-550

Cottle, T. J., \& Pleck, J. H. (1969). Linear estimations of temporal extension: The effect of age, sex, and social class. Journal of Projective Techniques and Personality Assessment, 33, 81-93.

Cottle, T. J., Howard, P., \& Pleck, J. H. (1969). Adolescents perception of time: The effect of age, sex and social class. Journal of Personality, 37, 636-650.

D'Alessio, M., Guarino, A., De Pascalis, V., \& Zimbardo, P. G. (2003). Testing Zimbardo's Stanford time perspective inventory (STPI)-short form an Italian study. Time \& Society, 12, 333-347.

Daugherty, J. R., \& Brase, G. L. (2010). Taking time to be healthy: Predicting health behaviors with delay discounting and time perspective. Personality and Individual Differences, 48, 202-207.

Desmyter, F., \& De Raedt, R. (2012). The relationship between time perspective and subjective well-being of older adults. Psychologica Belgica, 52, 19-38.

DeVolder, M. (1979). Time orientation: a review. Psychologica Belgica, 12, 61-79

Donders, F.C. (1868). Die Schnelligkeit psychischer Prozesse. Archiv für Anatomie und Physiologie, 8, 657-681.

Drake, L., Duncan, E., Sutherland, F., Abernethy, C., \& Henry, C. (2008). Time perspective and correlates of wellbeing. Time \& Society, 17, 47-61.

Ely, R., \& Mercurio, A. (2011). Time perspective and autobiographical memory: Individual and gender differences in experiencing time and remembering the past. Time \& Society, 20, 375-400.

Ferrari, J. R., \& Díaz-Morales, J. F. (2007). Procrastination: Different time orientations reflect different motives. Journal of Research in Personality, 41, 707-714. 
Fieulaine, N. (2006). Perspective temporelle, situations de précarité et santé: Une approche psychosociale du temps (Doctoral dissertation, Université de Provence-Aix-Marseille I).

Fieulaine, N., \& Apostolidis, T. (2015). Precariousness as a time horizon: How poverty and social insecurity shape individuals' time perspectives. In M. Stolarski, N. Fieulaine, \& van Beek, W. (Eds.), Time perspective theory: Review, research, and application (pp. 213-228). Cham, Switzerland: Springer International Publishing.

Fieulaine, N., \& Martinez, F. (2010). Time under control: Time perspective and desire for control in substance use. Addictive Behaviors, 35, 799-802.

Frank, L. K. (1939). Time perspectives. Journal of Social Philosophy, 4, 293-312.

Fredrickson, B. L. (2009). Positivity. New York, NY: Crown Publishers.

Frisch, M. B. (2006). Quality of life therapy. Hoboken, NJ: Wiley.

García, J. A., \& Ruiz, B. (2015). Exploring the role of time perspective in leisure choices: What about the balanced time perspective? Journal of Leisure Research, 47, 515-537.

Gartstein, M. A., \& Rothbart, M. K. (2003). Studying infant temperament via the revised infant behavior questionnaire. Infant Behavior and Development, 26, 64-86.

Gillespie, J., \& Allport, G. (1955). Youth's outlook on the future. Garden City, NY: Doubleday.

Gilovich, T., Medvec, V. H., \& Kahneman, D. (1998). Varieties of regret: A debate and partial resolution. Psychological Review, 105, 602-605.

Gladden, P. R., Figueredo, A. J., \& Jacobs, W. J. (2009). Life history strategy, psychopathic attitudes, personality, and general intelligence. Personality and Individual Differences, 46, 270-275.

Gonzalez, A., \& Zimbardo, P. G. (1985, May). Time in perspective: A Psychology Today survey report. Psychology Today, 21-26. 
Green, L., \& Myerson, J. (2004). A discounting framework for choice with delayed and probabilistic rewards. Psychological Bulletin, 130, 769-792.

Gruber, J., Cunningham, W. A., Kirkland, T., \& Hay, A. C. (2012). Feeling stuck in the present? Mania proneness and history associated with present-oriented time perspective. Emotion, 12, 13-17.

Guo, Y., Chen, Z., \& Feng, T. (2017). Neural substrates underlying balanced time perspective: A combined voxel-based morphometry and resting-state functional connectivity study. Behavioural Brain Research, 332, 237-242.

Guyau, J. M. (1890). La genèse de l'idée de temps. Paris: Alcan.

Hall E. T. (1966). The hidden dimension. Garden City, NY: Doubleday.

Harber, K. D., Zimbardo, P. G., \& Boyd, J. N. (2003). Participant self-selection biases as a function of individual differences in time perspective. Basic and Applied Social Psychology, 25, 255-264.

Heidegger, M. (1927). Etre et temps. Paris: Gallimard.

Henson, J. M., Carey, M. P., Carey, K. B., \& Maisto, S. A. (2006). Associations among health behaviors and time perspective in young adults: Model testing with boot-strapping replication. Journal of Behavioral Medicine, 29, 127-137.

Hodgins, D. C., \& Engel, A. (2002). Future time perspective in pathological gamblers. Journal of Nervous and Mental Disease, 190, 775-780.

Hofstede, G., \& Minkov, M. (2010). Long-versus short-term orientation: New perspectives. Asia Pacific Business Review, 16, 493-504.

Holman, E. A., \& Silver, R. C. (1998). Getting "stuck" in the past: Temporal orientation and coping with trauma. Journal of Personality and Social Psychology, 74, 1146-1163.

Holman, E. A., \& Silver, R. C. (2005). Future-oriented thinking and adjustment in a nationwide longitudinal study following the September 11th terrorist attacks. 
Motivation and Emotion, 29, 385-406.

Homewood, J., Mahmut, M., Meiser, B., Taylor, A., \& Wakefield, C. E. (2010). Time perspective in hereditary cancer: Psychometric properties of a short form of the Zimbardo Time Perspective Inventory in a community and clinical sample. Genetic Testing and Molecular Biomarkers, 14, 617-627.

Horne, J. A., \& Östberg, O. (1975). A self-assessment questionnaire to determine morningness-eveningness in human circadian rhythms. International Journal of Chronobiology, 4, 97-110.

Horstmanshof, L., \& Zimitat, C. (2007). Future time orientation predicts academic engagement among first-year university students. British Journal of Educational Psychology, 77, 703-718.

Hulett, J. E. (1944). The person's time perspective and the social role. Social Forces, 23, 155159.

Husman, J., \& Shell, D. F. (2008). Beliefs and perceptions about the future: A measurement of future time perspective. Learning and Individual Differences, 18, 166-175.

Husserl, E. (1928). Leçons sur la conscience intime du temps. Paris: Presses Universitaires de France.

Israeli, N. (1932). Wishes concerning improbable future events: Reactions to the future. Journal of Applied Psychology, 16, 584-588.

James, W. (1890). The principles of psychology. New York, NY: Dover.

Janet, P. (1928). L'évolution de la mémoire et de la notion de temps. Paris: Chahine.

Jaroni, J. L., Wright, S. M., Lerman, C., \& Epstein, L. H. (2004). Relationship between education and delay discounting in smokers. Addictive Behaviors, 29, 1171-1175.

Jochemczyk, Ł., Pietrzak, J., Buczkowski, R., Stolarski, M., \& Markiewicz, Ł. (2017). You only live once: present-hedonistic time perspective predicts risk propensity. 
Personality and Individual Differences, 115, 148-153.

Judge, T. A., \& Ilies, R. (2002). Relationship of personality to performance motivation: A meta-analytic review. Journal of Applied Psychology, 87, 797-807.

Jung, C. G. (1939/1980). Collected Works. Vol. 9, Part 1. The Archetypes and the Collective Unconscious. Princeton, NJ: Princeton University Press, Bollingen Series.

Kaplan, H., \& Gangestad, S. (2005). Life history theory and evolutionary psychology. In D. M. Buss (Ed.), The handbook of evolutionary psychology (pp. 68-95). Hoboken, NJ: John Wiley and Sons.

Kashdan, T. B., Rose, P., \& Fincham, F. D. (2004). Curiosity and exploration: Facilitating positive subjective experiences and personal growth opportunities. Journal of Personality Assessment, 82, 291-305.

Kastenbaum, R. (1961). The dimensions of future time perspective, an experimental analysis. The Journal of General Psychology, 65, 203-218.

Kazakina, E. (2015). The uncharted territory: Time perspective research meets clinical practice. Temporal focus in psychotherapy across adulthood and old age. In M. Stolarski, N. Fieulaine, \& W. van Beek (Eds.), Time perspective theory: Review, research, and application (pp. 499-516). Cham, Switzerland: Springer International Publishing.

Keough, K. A., Zimbardo, P. G., \& Boyd, J. N. (1999). Who's smoking, drinking, and using drugs? Time perspective as a predictor of substance use. Basic and Applied Social Psychology, 21, 149-164.

Košt’ál, J., Klicperová-Baker, M., Lukavská, K., \& Lukavský, J. (2016). Short version of the Zimbardo Time Perspective Inventory (ZTPI-short) with and without the FutureNegative scale, verified on nationally representative samples. Time \& Society, 25, 169192. 
Kovač, V. B., \& Rise, J. (2007). The relation between past behavior, intention, planning, and quitting smoking: The moderating effect of future orientation. Journal of Applied Biobehavioral Research, 12, 82-100.

Labov, W. (1997). Some further steps in narrative analysis. Journal of Narrative and Life History, 7, 395-415.

Laghi, F., Baiocco, R., D'Alessio, M., \& Gurrieri, G. (2009). Suicidal ideation and time perspective in high school students. European Psychiatry, 24, 41-46.

Lamm, H., Schmidt, R. W., \& Trommsdorff, G. (1976). Sex and social class as determinants of future orientation in adolescents. Journal of Personality and Social Psychology, 34, 317-326.

Lennings, C. J., Burns, A. M., \& Cooney, G. (1998). Profiles of time perspective and personality: Developmental considerations. The Journal of Psychology, 132, 629-641.

Lens, W. (1986). Future time perspective: A cognitive-motivational concept. In D. R. Brown \& J. Veroff (Eds.), Frontiers of motivational psychology (pp. 173-190). New York, NY: Springer.

Lens, W., Paixao, M. P., Herrera, D., \& Grobler, A. (2012). Future time perspective as a motivational variable: Content and extension of future goals affect the quantity and quality of motivation. Japanese Psychological Research, 54, 321-333.

LeShan, L. L. (1952). Time orientation and social class. Journal of Abnormal and Social Psychology, 47, 589-592.

Levine, R. V., \& Norenzayan, A. (1999). The pace of life in 31 countries. Journal of Crosscultural Psychology, 30, 178-205.

Lewin, K. (1942). Time perspective and morale. In G. Watson (Ed.), Civilian morale (pp. 4870). Boston, MA: Houghton Mifflin.

Lewin, K. (1946). Behavior and development as a function of the total situation. In L. 
Carmichael (Ed.), Manual of child psychology (pp. 791-844). New York, NY: Wiley.

Lewin, K. (1951). Field theory in social sciences. New York, NY: Harper.

Maglio, S. J., Trope, Y., \& Liberman, N. (2015). From time perspective to psychological distance (and back). In M. Stolarski, N. Fieulaine, \& W. van Beek (Eds.), Time perspective theory: Review, research, and application (pp. 143-154). Cham, Switzerland: Springer International Publishing.

Martinez, F., \& Fieulaine, N. (2015). Time and the misfits: Temporal framing and priming in persuasive communication. In M. Stolarski, N. Fieulaine, \& W. van Beek (Eds.), Time perspective theory: Review, research, and application (pp. 385-402). Cham,

Switzerland: Springer International Publishing.

Martz, E., \& Livneh, H. (2007). Do posttraumatic reactions predict future time perspective among people with insulin-dependent diabetes mellitus? Rehabilitation Counseling Bulletin, 50, 87-98.

Matthews, G., \& Stolarski, M. (2015). Emotional processes in development and dynamics of individual time perspective. In M. Stolarski, N. Fieulaine, \& W. van Beek (Eds.), Time perspective theory: Review, research, and application (pp. 269-286). Cham,

Switzerland: Springer International Publishing.

McAdams, D. P. (1995). What do we know when we know a person? Journal of Personality, 63(3), 365-396.

McAdams, D. P., \& Olson, B. D. (2010). Personality development: Continuity and change over the life course. Annual Review of Psychology, 61, 517-542.

McElwee, R. O. B., \& Haugh, J. A. (2010). Thinking clearly versus frequently about the future self: Exploring this distinction and its relation to possible selves. Self and Identity, 9, 298-321.

McKay, M. T., Andretta, J. R., Magee, J., \& Worrell, F. C. (2014). What to temporal profiles 
tell us about adolescent alcohol use? Results from a large sample in the United Kingdom. Journal of Adolescence, 37, 1319-1328.

McKay, M. T., Cole, J. C., \& Andretta, J. R. (2016). Temporal profiles relate meaningfully to anxiety and depression in university undergraduates. Personality and Individual Differences, 101, 106-109.

McKay, M. T., Cole, J. C., Percy, A., Worrell, F. C., \& Mello, Z. R. (2015). Reliability and factorial validity of Adolescent Time Inventory-Time Attitude (ATI-TA) scores in Scottish and Northern Irish adolescents. Personality and Individual Differences, 86, $412-416$.

Mead, G. H. (1932). The philosophy of the present. Chicago, IL: Open Court.

Meade, R. D. (1971). Future time perspective of college students in America and India. Journal of Social Psychology, 83, 175-182.

Mello, Z. R., \& Worrell, F. C. (2007). The Adolescent Time Inventory - English. Berkeley, CA: The University of California (Retrieved from https://faculty.sfsu.edu/ zmello/content/adolescent-time-inventory).

Mello, Z. R., \& Worrell, F. C. (2015). The past, the present, and the future: A conceptual model of time perspective in adolescence. In M. Stolarski, N. Fieulaine, \& W. van Beek (Eds.), Time perspective theory: Review, research, and application (pp. 115129). Cham, Switzerland: Springer International Publishing.

Mello, Z. R., Finan, L. J., \& Worrell, F. C. (2013). Introducing an instrument to assess time orientation and time relation in adolescents. Journal of Adolescence, 36, 551-563.

Mello, Z. R., Zhang, J. W., Barber, S. J., Paoloni, V. C., Howell, R. T., \& Worrell, F. C. (2016). Psychometric properties of time attitudes scores in young, middle, and older adult samples. Personality and Individual Differences, 101, 57-61.

Milfont, T. L., \& Demarque, C. (2015). Understanding environmental issues with temporal 
lenses: Issues of temporality and individual differences. In M. Stolarski, N. Fieulaine, \& W. van Beek (Eds.), Time perspective theory: Review, research, and application (pp. 371-383). Cham, Switzerland: Springer International Publishing.

Milfont, T. L., \& Schwarzenthal, M. (2014). Explaining why larks are future-oriented and owls are present-oriented: Self-control mediates the chronotype-time perspective relationships. Chronobiology International, 31, 581-588.

Milfont, T. L., Andrade, P. R., Belo, R. P., \& Pessoa, V. S. (2008). Testing Zimbardo time perspective inventory in a Brazilian sample. Interamerican Journal of Psychology, 42, 49-58.

Milfont, T. L., Wilson, J., \& Diniz, P. (2012). Time perspective and environmental engagement: A meta-analysis. International Journal of Psychology, 47, 325-334.

Minkowski, E. (1933). Le temps vécu: Etude phénoménologique et psychopathologique. Paris: PUF.

Mischel, W., Shoda, Y., \& Rodriguez, M. L. (1989). Delay of gratification in children. Science, 244, 933-938.

Molinari, L., Speltini, G., Passini, S., \& Carelli, M. G. (2016). Time perspective in adolescents and young adults: Enjoying the present and trusting in a better future. Time \& Society, 25, 594-612.

Murray, H. A. (1955). American Icarus. Clinical Studies of Personality, 2, 615-641.

Nurmi, J. E. (1991). How do adolescents see their future? A review of the development of future orientation and planning. Developmental Review, 11, 1-59.

Nuttin, J. (1980). Motivation et perspectives d'avenir. Louvain: Presses universitaires de Louvain.

Nuttin, J. R. (1964). The future time perspective in human motivation and learning. Acta Psychologica, 23, 60-82. 
Nuttin, J. R. (1985). Future time perspective and motivation: Theory and research method. Hillsdale, NJ: Erlbaum.

O’Rand, A., \& Ellis, R. A. (1974). Social class and social time perspective. Social Forces, 53, 53-62.

Olderbak, S., \& Figueredo, A. J. (2009). Predicting romantic relationship satisfaction from life history strategy. Personality and Individual Differences, 46, 604-610.

Oldham, J. M. \& Morris, L. B. (1995). The new personality self-portrait: Why you think, work, love and act the way you do. New York, NY: Bantam.

Olivera-Figueroa, L. A., Juster, R. P., Morin-Major, J. K., Marin, M. F., \& Lupien, S. J. (2015). A time to be stressed? Time perspectives and cortisol dynamics among healthy adults. Biological Psychology, 111, 90-99.

Oniszczenko, W., Zawadzki, B., Strelau, J., Riemann, R., Angleitner, A., \& Spinath, F. M. (2003). Genetic and environmental determinants of temperament: A comparative study based on Polish and German samples. European Journal of Personality, 17, 207-220.

Orbell, S., \& Hagger, M. (2006). Temporal framing and the decision to take part in type 2 diabetes screening: Effects of individual differences in consideration of future consequences on persuasion. Health Psychology, 25, 537.

Orkibi, H. (2015). Psychometric properties of the Hebrew short version of the Zimbardo Time Perspective Inventory. Evaluation and the Health Professions 38, 219-245.

Ortuño, V., Paixão, M. P. \& Janeiro, I. (2011). Diferenças na Perspectiva Temporal entre estudantes religiosos e não religiosos. Proceedings of VIII Congresso Iberoamericano de Avaliação Psicológica (pp. 74-84). Lisbon: University of Lisbon.

Osgood, C. E., Suci, G. J., \& Tannenbaum, P. H. (1978). The measurement of meaning. Urbana, IL: University of Illinois Press. 
Papastamatelou, J., Unger, A., Giotakos, O., \& Athanasiadou, F. (2015). Is time perspective a predictor of anxiety and perceived stress? Some preliminary results from Greece. Psychological Studies, 60, 468-477.

Pavlov, I. P. (1927). Conditioned reflexes: An investigation of the physiological activity of the cerebral cortex. London: Oxford University Press.

Peetsma, T. T. (2000). Future time perspective as a predictor of school investment. Scandinavian Journal of Educational Research, 44, 177-192.

Piaget, J. (1937). La construction du réel chez l'enfant. Neuchâtel: Delachaux et Niestlé.

Poole, M. E., \& Cooney, G. H. (1987). Orientations to the future: A comparison of adolescents in Australia and Singapore. Journal of Youth and Adolescence, 16, 129151.

Rabinovich, A., Morton, T., \& Postmes, T. (2010). Time perspective and attitude-behaviour consistency in future-oriented behaviours. British Journal of Social Psychology, 49, 69-89.

Rappaport, H., Enrich, K., \& Wilson, A. (1985). Relation between ego identity and temporal perspective. Journal of Personality and Social Psychology, 48, 1609-1620.

Roeckelein, J. E. (2000). The concept of time in psychology. Westport, CT: Greenwood Press. Roenneberg, T., Wirz-Justice, A., \& Merrow, M. (2003). Life between clocks: Daily temporal patterns of human chronotypes. Journal of Biological Rhythms, 18, 80-90.

Ronancio, A. M., Ward, K. K., \& Fernandez, M. E. (2014). The influence of time perspective on cervical cancer screening among Latinas in the United States. Journal of Health Psychology, 19, 1547-1553.

Rönnlund, M., Åström, E., \& Carelli, M. G. (2017). Time perspective in late adulthood: Aging patterns in past, present and future dimensions, deviations from balance, and associations with subjective well-being. Timing \& Time Perception, 5, 77-98. 
Ross, L. (1977). The intuitive psychologist and his shortcomings: Distortions in the attribution process. Advances in Experimental Social Psychology, 10, 174 -221.

Rothspan, S., \& Read, S. J. (1996). Present versus future time perspective and HIV risk among heterosexual college students. Health Psychology, 15, 131-134.

Ruiz, R. A., \& Krauss, H. H. (1968). Anxiety, temporal perspective and item content of the incomplete thoughts test (ITT). Journal of Clinical Psychology, 24, 70-72

Sansbury, B., Dasgupta, A., Guthrie, L., \& Ward, M. (2014). Time perspective and medication adherence among individuals with hypertension or diabetes mellitus. Patient Education and Counseling, 95, 104-110.

Seema, R., Sircova, A., \& Baltin, A. (2014). Transcendental future: Is it a healthy belief or a time perspective? The transcendental-future time perspective inventory (TTPI) in Estonian. Trames, 18, 57-75.

Shannon, L. (1975). Development of time perspective in three cultural groups: A cultural difference or an expectancy interpretation. Developmental Psychology, 11, 114-115.

Shipp, A. J., Edwards, J. R., \& Lambert, L. S. (2009). Conceptualization and measurement of temporal focus: The subjective experience of the past, present, and future. Organizational Behavior and Human Decision Processes, 110, 1-22.

Shoda, Y. (2004). Individual differences in social psychology: Understanding situations to understand people, understanding people to understand situations. In C. Sansone, C. C. Morf, \& A.T . Panter (Eds.), The SAGE handbook of methods in social psychology (pp. 117-141). Thousand Oakes, CA: Sage Publications.

Shores, K., \& Scott, D. (2007). The relationship of individual time perspective and recreation experience preferences. Journal of Leisure Research, 39, 28-59.

Simons, J., Vansteenkiste, M., Lens, W., \& Lacante, M. (2004). Placing motivation and future time perspective theory in a temporal perspective. Educational Psychology Review, 
$16,121-139$.

Sircova, A., \& Mitina, O. V. (2008). Age dynamics of time orientations [in Russian]. Voprosi Psikhologii, 2, 41-55.

Sircova, A., \& Osin, E. (2016). A hard nut to crack: ZTPI across 33 countries. Open data lab during the 3rd International Conference on Time Perspective. Copenhagen, Denmark, 15-19 August 2016.

Sircova, A., van de Vijver, F. J. R., Osin, E., Milfont, T. L., Fieulaine, N., Kislali-Erginbilgic, A., Zimbardo, P. G. and 54 members of the International Time Perspective Research Project. (2014). A global look at time: A 24-country study of the equivalence of the Zimbardo Time Perspective Inventory. SageOpen, 4, 1.

Sircova, A., van de Vijver, F. J., Osin, E., Milfont, T. L., Fieulaine, N., Kislali-Erginbilgic, A., \& Zimbardo, P. G. (2015). Time perspective profiles of cultures. In M. Stolarski, N. Fieulaine, \& W. van Beek (Eds.), Time perspective theory: Review, research, and application (pp. 169-187). Cham, Switzerland: Springer International Publishing.

Sobol-Kwapinska, M. (2009). Forms of present time orientation and satisfaction with life in the context of attitudes toward past and future. Social Behavior and Personality, 37, 433-440.

Sobol-Kwapinska, M. (2013). Hedonism, fatalism and 'carpe diem': Profiles of attitudes towards the present time. Time \& Society, 22, 371-390.

Sobol-Kwapinska, M., \& Jankowski, T. (2016). Positive time: Balanced time perspective and positive orientation. Journal of Happiness Studies, 17, 1511-1528.

Sobol-Kwapinska, M., Jankowski, T., \& Przepiorka, A. (2016). What do we gain by adding time perspective to mindfulness? Carpe Diem and mindfulness in a temporal framework. Personality and Individual Differences, 93, 112-117.

Stolarski, M. (2016). Not restricted by their personality: Balanced time perspective moderates 
well-established relationships between personality traits and well-being. Personality and Individual Differences, 100, 140-144.

Stolarski, M., \& Cyniak-Cieciura, M. (2016). Balanced and less traumatized: Balanced time perspective mediates the relationship between temperament and severity of PTSD syndrome in motor vehicle accident survivor sample. Personality and Individual Differences, 101, 456-461.

Stolarski, M., \& Matthews, G. (2016). Time perspectives predict mood states and satisfaction with life over and above personality. Current Psychology, 35, 516-526.

Stolarski, M., \& Witowska, J. (in press). Balancing own time perspective from aerial view: Metacognitive processes in temporal framing. In A. Kostic \& D. Chadee (Eds.), Time perspective: Theory and practice. New York, NY: Palgrave Macmillan.

Stolarski, M., Bitner, J., \& Zimbardo, P.G. (2011). Time perspective, emotional intelligence and discounting of delayed awards. Time \& Society, 20, 346-363.

Stolarski, M., Czarna, A. Z., Malesza, M., \& Szymańska, A. (2017). Here and now: Sociosexuality mediates the associations between Dark Triad and Time Perspectives (in females). Personality and Individual Differences, 111, 119-123.

Stolarski, M., Fieulaine, N., \& van Beek, W. (eds.)(2015). Time perspective theory: Review, research, and application. Cham, Switzerland: Springer International Publishing.

Stolarski, M., Ledzińska, M., \& Matthews, G. (2013). Morning is tomorrow, evening is today: Relationships between chronotype and time perspective. Biological Rhythm Research, $44,181-196$

Stolarski, M., Matthews, G., Postek, S., Zimbardo, P. G., \& Bitner, J. (2014). How we feel is a matter of time: Relationships between time perspectives and mood. Journal of Happiness Studies, 15, 809-827.

Stolarski, M., Vowinckel, J., Jankowski, K. S., \& Zajenkowski, M. (2016). Mind the balance, 
be contented: Balanced time perspective mediates the relationship between mindfulness and life satisfaction. Personality and Individual Differences, 93, 27-31.

Stolarski, M., Wiberg, B., \& Osin, E. (2015). Assessing temporal harmony: The issue of a balanced time perspective. In M. Stolarski, N. Fieulaine, \& W. van Beek (Eds.), Time perspective theory: Review, research, and application (pp. 57-71). Cham,

Switzerland: Springer International Publishing.

Stolarski, M., Wojtkowska, K., \& Kwiecińska, M. (2016). Time for love: Partners' time perspectives predict relationship satisfaction in romantic heterosexual couples. Time \& Society, 25, 552-574.

Stolarski, M., Zajenkowski, M., \& Zajenkowska, A. (2016). Aggressive? from time to time... uncovering the complex associations between time perspectives and aggression. Current Psychology, 35(4), 506-515.

Strathman, A., Gleicher, F., Boninger, D. S., \& Edwards, C. S. (1994). The consideration of future consequences: Weighing immediate and distant outcomes of behavior. Journal of Personality and Social Psychology, 66, 742-752.

Strelau, J. (1996). The regulative theory of temperament: Current status. Personality and Individual Differences, 20, 131-142.

Suddendorf, T., \& Busby, J. (2005). Making decisions with the future in mind: Developmental and comparative identification of mental time travel. Learning and Motivation, 36, 110-125.

Suddendorf, T., \& Corballis, M. C. (1997). Mental time travel and the evolution of the human mind. Genetic, Social, and General Psychology Monographs, 123, 133-167.

Suddendorf, T., \& Corballis, M. C. (2007). The evolution of foresight: What is mental time travel, and is it unique to humans? Behavioral and Brain Sciences, 30, 299-313.

Sword, R. M., Sword, R. K., Brunskill, S. R., \& Zimbardo, P. G. (2014). Time perspective 
therapy: A new time-based metaphor therapy for PTSD. Journal of Loss and Trauma, 19, 197-201.

Thiebaut, E. (1997). La perspective temporelle, l'objet de mesure vers une élucidation conceptuelle (Unpublished Doctoral dissertation, Université de Nancy II).

Tolman, E. C. (1932). Purposive behavior in man and animals. New York, NY: AppletonCentury-Crofts.

Tulving, E. (2002). Episodic memory: From mind to brain. Annual Review of Psychology, 53, $1-25$.

Turkheimer, E. (2000). Three laws of behavior genetics and what they mean. Current Directions in Psychological Science, 9, 160-164.

Unger, A., Yan, J., \& Busch, R. (in press). The relationship between the Zimbardo Time Perspective Inventory and violations of business ethics in China: Unbalanced time perspective increases the acceptance of unethical business behavior. Time \& Society.

Usunier, J. C., \& Valette-Florence, P. (2007). The Time Styles Scale: A review of developments and replications over 15 years. Time \& Society, 16, 333-366.

van Beek, W., \& Kairys, A. (2015). Time perspective and transcendental future thinking. In M. Stolarski, N. Fieulaine, \& W. van Beek (Eds.), Time perspective theory: Review, research, and application (pp. 73-86). Cham, Switzerland: Springer International Publishing.

van Beek, W., Berghuis, H., Kerkhof, A., \& Beekman, A. (2011). Time perspective, personality and psychopathology: Zimbardo's time perspective inventory in psychiatry. Time \& Society, 20, 364-374.

van Beek, W., Kerkhof, A., \& Beekman, A. (2009). Future oriented group training for suicidal patients: A randomized clinical trial. BMC Psychiatry, 9, 65.

Van Ittersum, K. (2012). The effect of decision makers' time perspective on intention- 
behavior consistency. Marketing Letters, 23, 263-277.

Vansteenkiste, M., Simons, J., Lens, W., Soenens, B., Matos, L., \& Lacante, M. (2004). Less is sometimes more: Goal content matters. Journal of Educational Psychology, 96, $755-764$.

Vázquez, S. M., Difabio de Anglat, H. E., \& Noriega Biggio, M. (2016). Perspectiva temporal y estilos de personalidad en estudiantes argentinos. Interdisciplinaria, 33, 315-336.

Vinkers, C. D., Adriaanse, M. A., \& de Ridder, D. T. (2013). In it for the long haul: Characteristics of early and late drop out in a self-management intervention for weight control. Journal of Behavioral Medicine, 36, 520-530.

Vowinckel, J. C., Westerhof, G. J., Bohlmeijer, E. T., \& Webster, J. D. (2017). Flourishing in the now: Initial validation of a present-eudaimonic time perspective scale. Time \& Society, 26, 203-226.

Wallace, M. (1956). Future time perspective in schizophrenia. Journal of Abnormal and Social Psychology, 52, 240-245.

Wallace, M., \& Rabin, A. I. (1960). Temporal experience. Psychological Bulletin, 57, 213236.

Wardle, J., \& Steptoe, A. (2003). Socioeconomic differences in attitudes and beliefs about healthy lifestyles. Journal of Epidemiology \& Community Health, 57, 440-443.

Webster, J. D. (2011). A new measure of time perspective: Initial psychometric findings for the Balanced Time Perspective Scale (BTPS). Canadian Journal of Behavioural Science, 43, 111-118.

Webster, J. D., \& Ma, X. (2013). A balanced time perspective in adulthood: Well-being and developmental effects. Canadian Journal on Aging, 32, 433-442.

Webster, J. D., Bohlmeijer, E. T., \& Westerhof, G. J. (2014). Time to flourish: The relationship of temporal perspective to well-being and wisdom across adulthood. 
Aging \& Mental Health, 18, 1046-1056.

Witkin, H. A., Moore, C. A., Goodenough, D. R., \& Cox, P. W. (1977). Field dependent and field independent cognitive styles and their educational implications. Review of Educational Research, 47, 1-64.

Wittmann, M. (2013). The inner sense of time: How the brain creates a representation of duration. Nature Reviews. Neuroscience, 14, 217-223.

Wittmann, M., \& Paulus, M. P. (2008). Decision making, impulsivity and time perception. Trends in Cognitive Sciences, 12, 7-12.

Wittmann, M., Rudolph, T., Linares Gutierrez, D., \& Winkler, I. (2015). Time perspective and emotion regulation as predictors of age-related subjective passage of time. International Journal of Environmental Research and Public Health, 12, 1602716042.

Worrell, F. C., \& Mello, Z. R. (2007). Reliability and validity of Zimbardo Time Perspective Inventory scores in academically talented adolescents. Educational and Psychological Measurement, 67, 487-504.

Worrell, F. C., Mello, Z. R., \& Buhl, M. (2013). Introducing English and German versions of the Adolescent Time Attitude Scale (ATAS). Assessment, 4, 496-510.

Wundt, W. (1910). Psychologismus und Logizismus. Kleine Schriften, Band I. Leipzig: Engelmann.

Zajenkowski, M., Stolarski, M., Maciantowicz, O., Malesza, M., \& Witowska, J. (2016). Time to be smart: Uncovering a complex interplay between intelligence and time perspectives. Intelligence, 58, 1-9.

Zajenkowski, M., Stolarski, M., Witowska, J., Maciantowicz, O., \& Łowicki, P. (2016). Fluid intelligence as a mediator of the relationship between executive control and balanced time perspective. Frontiers in Psychology, 7, 1844. 
Zaleski, Z. (1994). Psychology of future orientation. Lublin: Towarzystwo Naukowe KUL.

Zaleski, Z. (1996). Future anxiety: Concept, measurement, and preliminary research. Personality and Individual Differences, 21, 165-174.

Zhang, J. W., \& Howell, R. T. (2011). Do time perspectives predict unique variance in life satisfaction beyond personality traits? Personality and Individual Differences, 50, 1261-1266.

Zhang, J. W., Howell, R. T., \& Bowerman, T. (2013). Validating a brief measure of the Zimbardo Time Perspective Inventory. Time \& Society, 22, 391-409.

Zhang, J. W., Howell, R. T., \& Stolarski, M. (2013). Comparing three methods to measure a balanced time perspective: The relationship between a balanced time perspective and subjective well-being. Journal of Happiness Studies, 14, 169-184.

Zimbardo, P. G., \& Boyd, J. N. (2008). The time paradox. New York, NY: Free Press.

Zimbardo, P. G., \& Boyd, J. N. (1999). Putting time in perspective: A valid, reliable individual-differences metric. Journal of Personality and Social Psychology, 77, 1271-1288.

Zimbardo, P. G., Clements, N., \& Karimzad, B. (2016). Credit cards - the ultimate present hedonist trap. Oral presentation delivered during the 3rd International Conference on Time Perspective. Kopenhagen, 15-19 August 2016.

Zimbardo, P. G., \& Gonzalez, A. (1984, February). A Psychology Today reader survey. Psychology Today, pp. 53-54.

Zimbardo, P. G., Haney, C., Banks, W. C., \& Jaffe, D. (1973). A Pirandellian prison: The mind is a formidable jailer. New York Times Magazine, 8, 38-60.

Zimbardo, P. G., Keough, K. A., \& Boyd, J. N. (1997). Present time perspective as a predictor of risky driving. Personality and Individual Differences, 23, 1007-1023.

Zimbardo, P. G., Sword, R. M., \& Sword, R. K. (2012). The time cure: Overcoming PTSD 
with the new psychology of time perspective therapy. San Francisco, CA: Jossey-Bass.

Zimbardo, Z., McDermott, C. A. R. \& Zimbardo, P. G. (in press). Valid, reliable new factor of time perspective: The expanded present (XPTP). In Kostic, A. \& Chadee, D., Time Perspective: Theory and Practice. London: Palgrave-MacMillan.

Zuckerman, M. (1971). Dimensions of sensation seeking. Journal of Consulting and Clinical Psychology, 36, 45-52. 